Delft University of Technology

\title{
One-way shear strength of wide reinforced concrete members without stirrups
}

de Sousa, AlexM.D.; Lantsoght, Eva O.L.; El Debs, Mounir K.

DOI

10.1002/suco.202000034

Publication date

2020

Document Version

Accepted author manuscript

Published in

Structural Concrete

\section{Citation (APA)}

de Sousa, A. D., Lantsoght, E. O. L., \& El Debs, M. K. (2020). One-way shear strength of wide reinforced concrete members without stirrups. Structural Concrete, 22(2), 968-992.

https://doi.org/10.1002/suco.202000034

\section{Important note}

To cite this publication, please use the final published version (if applicable).

Please check the document version above.

\section{Copyright}

Other than for strictly personal use, it is not permitted to download, forward or distribute the text or part of it, without the consent of the author(s) and/or copyright holder(s), unless the work is under an open content license such as Creative Commons.

\section{Takedown policy}

Please contact us and provide details if you believe this document breaches copyrights.

We will remove access to the work immediately and investigate your claim. 
Title: One-way shear strength of wide reinforced concrete members without stirrups

Running head: Shear strength of wide members without stirrups

\section{Author 1}

P.h.D. candidate Alex M. D. de Sousa

University of São Paulo, São Carlos School of Engineering

Department of Structural Engineering

Av. Trabalhador Sãocarlense, 400, 13566-590,

Sao Carlos, Brazil

Phone: (+55) 1633739474

Orcid ID: 0000-0003-0424-4080

alex_dantas@usp.br

\section{Author 2}

Dr. ir. Eva O.L. Lantsoght

Politécnico, Universidad San Francisco de Quito

Diego de Robles y Pampite, Cumbaya, Quito, Ecuador

Phone: (+593) 2 297-1700

Orcid ID: 0000-0003-4548-7644

elantsoght@usfq.edu.ec

Concrete Structures, Delft University of Technology

P.O. Box 5048, 2600 GA Delft, The Netherlands

E.O.L.Lantsoght@tudelft.nl

\section{Author 3}

Dr. ir. Mounir K. El Debs

University of São Paulo, São Carlos School of Engineering,

Department of Structural Engineering,

Av. Trabalhador Sãocarlense, 400, 13566-590,

São Carlos, Brazil

Phone: (+55) 1633739474

Orcid ID: 0000-0001-5955-7936

mkdebs@sc.usp.br 


\section{Abstract}

The calibration of most analytical models that assess the shear strength of wide reinforced concrete members without shear reinforcement is traditionally based on simply-supported beam tests, which may not be representative of slabs and wide members failing in shear. This paper addresses the knowledge on the shear strength of wide members, identification of their most important parameters, and an evaluation of the accuracy and precision of the main models presented in codes of practice and literature. A database of 170 shear tests on wide members loaded over the entire width, with the ratio width to effective depth $b / d>1$. This database includes members under concentrated loads and distributed loads in the span direction. A parameter analysis revealed such shear strength is mostly influenced by the shear slenderness and size effect rather than by the ratio $b / d$. Furthermore, the results show a clear decrease in the shear strength of continuous members under distributed loads to higher shear slenderness, similar to the behavior of members under concentrated loads. This trend was better observed with a proposed model of shear slenderness, which assumes that continuous members with higher bending moment in the span than in the support behave closer to simply supported members. A comparison of the shear capacities predicted by the physicalmechanical and semi-empirical approaches showed the higher accuracy and precision of models based on the Critical Shear Crack Theory (CSCT) and Critical Shear Displacement Theory (CSDT), regardless of the ratio $b / d$. Therefore, the same models derived based on beam-tests are valid for wide members. Apart from that, the analyses of non-slender members with strain-based models combined with reducing factors of the acting shear load provide accurate results of shear strength for members without stirrups.

Keywords: database of shear tests, one-way shear strength, shear slenderness, reinforced concrete members without stirrups, wide reinforced concrete members. 


\section{Introduction}

Reinforced concrete (RC) one-way slabs and wide beams are structural members extensively used in residential buildings, for bridge deck slabs and as transfer elements (Calvi, et al., 2018; Lubell et al., 2004). Since these members generally do not contain shear reinforcement, the assessment of shear capacity may be critical due to the brittle nature of shear failures. By not taking into account the size effect in thicker members (Bazant \& Kim, 1984) and the reduced aggregate interlock capacity in cracks of high strength concrete (Yang et al., 2016), some older design codes could provide higher shear capacities than the real ones in the assessment of existing structures. Besides, the shear reinforcement may be undesirable in design since it is not cost-effective for large members and can result in reinforcement congestion. Therefore, efforts have been devoted towards the development of reliable and accurate models of shear strength for members without shear reinforcement.

Another matter of concern regarding the shear capacity of RC members is the suitability of current code provisions for assessment of wide members. The current code provisions and main design models for shear (ACI Committee 318, 2019; CEN, 2005; Fédération Internationale du Béton (fib), 2012) have been calibrated by shear tests on narrow beams, with width to effective depth $b / d<1$. Such beams may not be representative for wide members, whose $b / d$ ratio is higher than 1 . A database analysis conducted by Gurutzeaga et al. (2015) revealed the member width $b$ does not appear to influence the shear strength of wide members significantly. On the other hand, Conforti et al. (2017) observed shear strength increases approximately $25 \%$ when the $b / d$ ratio increases from 1 to 3 .

Such different results have lead us to identify the need for a more comprehensive study that includes tests of wide members under different load arrangements and support conditions. Term line loads are used here to describe members loaded at the full width (Figure 1a) on the top view - observe both members in Figure 1a,b are subjected to concentrated loads 
in the span direction, while in Figure 1b, the load is not applied along with the full width. On slabs whose load is concentrated in small areas, e.g. wheel loads on bridge decks, not all the width of the slab width contribute to the shear strength (Lantsoght et al., 2013). Therefore, an effective width combined with a one-way shear model is used for the calculation of the shear capacity. Our study focuses on slabs and wide beams loaded over the full width as the first step for a better understanding of the problem of wide members under shear loads with no influence of an effective width model. Figure 1c shows a wide member under line load in the width direction and a uniformly distributed load in the span direction, such as in a cut-incover tunnel slab, whose distributed loads can be the main loads (Sigrist et al., 2013).

Apart from geometric differences between narrow beams and wide members (e.g., slabs and wide beams), several design codes (ABNT, 2014; CEN, 2005) have established semi-empirical formulas for analyses of shear strength. Although these formulations are easier for the day-use due to its closed-form, most of them show the following limitations: (i) safety is not guaranteed beyond the boundaries of calibration, (ii) very conservative results can be achieved under usual loads (Kuchma et al., 2019), specifically in the case of higher axial tensile loads (Jørgensen et al., 2013), (iii) aggregate size $d_{g}$, which plays a fundamental role in the aggregate interlock is not considered, and (iv) current provisions for the size effect can yield unsafe predictions of shear strength for members of higher effective depths. Several mechanical models have been proposed towards overcoming such limitations. They have taken into account the contributions of one or more shear-carrying mechanisms, i.e. capacity of the uncracked compression zone (Reineck, 1991b; Taylor, 1974), aggregate interlock (Walraven, 1981), dowel action (Chana, 1987) and residual tensile strength of concrete across the crack (Gastebled \& May, 2001; Reineck, 1991a, 1991b). Since Conforti et al. (2017) verified the cracking pattern of wide members with $b / d>1$ ratio significantly differs from that 
of beams with $b / d<1$, some shear-carrying mechanisms are expected to change according to the $b / d$ ratio, which has not been appropriately investigated.

Figure 2 shows some differences in the cracking pattern of members with different $b / d$ ratios, identified by Conforti et al. (2017). Although the same material and reinforcement layouts are used, the cracking pattern along width direction $b$ is more irregular in case 2 for the wider member. We attribute this behavior to any irregularity in the load application or support condition and more pronounced randomness of cracking formation in the absence of shear reinforcement for large widths. Such an irregularity leads to larger cracked surfaces, which improves the aggregate interlock and can increase the shear capacity (Conforti et al., 2017). Another clear distinction is a higher number of flexural cracks develop with minor spacing in members with a higher $b / d$ ratio $\left(S_{r 1}>S_{r 2}\right.$ in Figure 2). Furthermore, flexural cracks that develop in members with higher $b / d$ ratios may not propagate from one face to another due to the more irregular crack profile. Improvements in the aggregate interlock promote higher shear displacements in the critical shear crack accompanied by a larger number of flexural cracks. However, these observations apply for tests under the same load and support conditions.

Most models place the critical section close to the higher moment-to-shear $M / V d$ ratio (fib, 2012; Muttoni \& Ruiz, 2008). However, according to other authors (Marí et al., 2015; Marí et al., 2014; Tung \& Tue, 2016a, 2016b), the critical section is placed closer to the position where the bending moment reaches the cracking moment. Since these models are based on different failure criteria, a comparison of the accuracy provided by these models could point which one better represents the shear failure. Here, moment-to-shear ratio $M / V d$ or shear slenderness $\lambda$ represents a normalized parameter of solicitation in the shear span. 
According to Eq. (1), in simply supported members under concentrated loads, the $M / V d$ ratio can be approximated by the shear span to depth ratio $a / d$ :

$$
\lambda=\frac{M}{V \cdot d}=\frac{V \cdot a}{V \cdot d}=\frac{a}{d}
$$

In simply supported members under distributed loads, since the shear force in the section of the maximum internal moment is zero, their shear slenderness is defined by the maximum sectional forces in the span, regardless of the sections (Adam et al., 2019):

$$
\lambda=\frac{M}{V \cdot d}=\frac{\left(\frac{q \cdot l}{2} \cdot \frac{l}{2}-q \cdot \frac{l}{2} \cdot \frac{l}{4}\right)}{\frac{q \cdot l}{2} \cdot d}=\frac{\frac{q \cdot l^{2}}{8}}{\frac{q \cdot l}{2} d}=\frac{l}{4 d}=\frac{a_{e q}}{d}
$$

where $a_{e q}$ can be interpreted as an equivalent shear span defined for simply supported members under uniformly distributed loads.

We propose joining the available test results of wide members with shear failures and discussing their behavior under different load arrangements and support conditions/structural systems. In comparison to the databases developed by Gurutzeaga et al. (2015) and Conforti et al. (2017), our database includes a more significant number of test results (170) and different structural systems, which were used for the identification of the main parameters that influence the shear strength of wide members. Furthermore, these results were used in an assessment of semi-empirical and mechanical-based models of shear strength according to (i) the structural system (ii) $b / d$ ratio, and (iii) shear slenderness $\lambda$. Our aim is to investigate whether geometric differences, load arrangements and support conditions, influence the shear strength of wide members significantly. 


\section{Literature review}

\subsection{Structural system or effect of support conditions}

Recent measurements of the contribution of each shear transfer action to members of different structural systems and load arrangements have shown no unique shear-transfer action governs the shear strength (Cavagnis et al., 2015, 2018). The contribution of different shear transfer mechanisms can vary according to the location, shape, and kinematics of the critical shear crack. Tung and Tue (2016b) observed some members, such as cantilevers under uniformly distributed loads, can be favored regarding shear strength by higher bending moments close to the support. Therefore, questions on a possible influence of the structural system and load arrangement on the main shear-carrying mechanisms may be raised.

As highlighted by Muttoni and Fernandez Ruiz (2008), simply supported beams can develop an arching action through a combination of an elbow-shaped strut, enabled by the tensile strength of concrete, and direct compressive struts disturbed or not by flexural cracks. Figure 3 shows the main difference between cantilever and simply supported members failing by shear is the self-weight action in the same direction of the main shear load for cantilever members and in the opposite direction for simply supported members. Therefore, higher differences in the shear behavior according to the structural system may appear if the selfweight is the main action.

One-way shear models consider the structural system or support conditions indirectly by calculations of internal forces $M$ and $V$ ( $M$ is the bending moment and $V$ is the shear force. The critical section in models based on the Modified Compression Field Theory (MCFT)(Vecchio \& Collins, 1986) and Critical Shear Crack Theory (CSCT)(Muttoni \& Ruiz, 2008 ) is usually close to the section of higher $M / V d$, where $d$ is the effective depth. These models predict the shear strength has an inverse relation with longitudinal concrete strain $\varepsilon$ in 
the critical section, which is directly associated with bending moment $M$. However, according to some experimental results (Caldentey et al., 2012; Tung \& Tue, 2016b) the shear strength of members such as cantilever under uniformly distributed loads may benefit from higher bending moment in the section of larger $M / V d$ ratio. Therefore, for such cases, the shear behavior may not be well described without considering the structural system and load arrangement, which can influence the contributions of the main shear-carrying mechanisms. In models such as MCFT and CSCT, the aggregate interlock is assumed as the main shear transfer action when a critical shear crack arises. However, in cantilever members under distributed loads, the higher bending moment close to the support can improve the compression chord capacity in such a way that the total shear strength can be improved instead of reduced (Tung \& Tue, 2016b).

\subsection{Degree of rotational restraint and shear slenderness}

Islam et al. (1998), Reißen (2016) and Reißen et al. (2018) investigated the effect of continuous systems by measuring the degree of rotational restraint of slabs on supports, $d_{r}$, of continuous members. However, such studies were limited to members subjected to concentrated loads in the span. Parameter $d_{r}$ can be estimated by Eq. (3) as follows:

$$
d_{r}(\%)=\frac{M_{\text {sup }}}{M_{e s t}} \cdot 100
$$

where $M_{\text {sup }}$ represents the bending moment produced by a cantilever load $f$ near the continuous support and $M_{e s t}$ represents the static moment for a fully clamped support (Figure 4). Another way to evaluate the degree of rotation restraint over the internal support in continuous members is to calculate the ratio $a_{1} / a_{2}$ (distances $a_{1}$ and $a_{2}$ are illustrated in Figure 4a separated by the location of the point of inflection in the bending moment graph). Such distances can be evaluated from bending moment diagrams, or using the theorem of 
intersecting lines for single loads (Islam, Pam, \& Kwan, 1998; Reißen, 2016). The higher $a_{1} / a_{2}$ ratio indicates a higher degree of rotational restraint at on continuous support.

On the other hand, the shear slenderness is a useful parameter for describing the shear failure modes of members without shear reinforcement, which will be discussed in the next sections. The literature provides the following shear slenderness definitions ( $\lambda$ ): (i) $a / d$ ratio, which is geometric relations between the shear span and the effective depth of members, mostly used in codes of practice (ABNT, 2014; SIA, 2013); (ii) $M / V d$ ratio, which directly expresses the ratio between the acting internal forces in a section and is equivalent to the $a / d$ ratio for simply supported members (ACI Committee 318,2014 ), and (iii) $\max \left(a_{1} ; a_{2}\right) / d$ ratio, which accounts for geometric information on the bending moment diagram and covers both simply supported and continuous members (Reißen, 2016).

Tung and Tue (2016b) observed when $M_{\text {span }}>M_{\text {sup }}$ in continuous members subjected to uniformly distributed loads (Figure 5a), the shear strength is approximately equal to that of simply supported members under uniformly distributed loads (Figure 5b). The authors highlighted if $M_{\text {span }}<M_{\text {sup }}$, the shear strength of continuous beams under distributed loads can be well approximated by the sum of two equivalent cantilevers, i.e., one loaded by the shear force at the point of inflection and another loaded by a distributed load (Figure 5c).

We propose taking into account the observations from Tung and Tue (2016b) for improving the shear slenderness definition of continuous members under distributed loads. We define the ratio $\max \left\{a_{1} ; a_{2}\right\} / d$ for such members, when $M_{s u p}<M_{\text {span }}$, is equal to that of simply supported members under uniformly distributed loads of reduced span length (Figure 5b). Table 1 shows a summary of calculations for the shear slenderness parameter:

\subsection{Load arrangement}


Figure 6 shows parameters $a_{1}$ and $a_{2}$ of continuous members under different load arrangements in the shear span, i.e., concentrated loads and uniformly distributed ones. Such definitions were used for the evaluation of tests with different load arrangements through a unique parameter as the $\max \left(a_{1} ; a_{2}\right) / d$ ratio.

Figure 7 illustrates three cases of load arrangement modifications, in which cantilever members under larger bending moments at the support show higher shear capacities in the span: (i) cantilever span under uniformly distributed loads compared to the same members under concentrated loads (Caldentey et al., 2012), (ii) longer cantilever members compared to short ones and (Tung \& Tue, 2016b) (iii) cantilever slabs under concentrated loads, in the span and width directions, combined or not with line loads along the full width (Reißen \& Hegger, 2013).

Caldentey et al. (2012) observed cantilever beams of constant thickness under uniformly distributed loads show a $27 \%$ higher capacity than those with concentrated loads in the shear span, which is against some mechanical-based models e.g. fib Model Code 2010 (fib, 2012) and CSCT (Muttoni \& Ruiz, 2008). An explanation is a critical shear crack can arise closer to the inner support with reduced shear displacements for some combinations of load arrangement and support conditions. The contribution of the aggregate interlock, i.e., the basis of the above-mentioned models, becomes of minor importance (Cavagnis et al., 2018). We can conclude the improvement in the compression chord capacity for cantilever spans under distributed loads can be more pronounced than the negative effect on the aggregate interlock at the critical shear crack.

\subsection{Shear failure modes}

The ratio between the clear shear span-to-effective depth ratio $a_{v} / d$ and the shear slenderness $M / V d$ or $\max \left(a_{1} ; a_{2}\right) / d$ can be used for distinguishing members subjected to 
compression-shear failures from those more susceptible to flexural-shear failure (Yang et al., 2017). As most models aim to describe second type failures, the accuracy level of models for members subjected to compression-shear failures is unknown. When the critical shear crack arises too close to the support, e.g., when concentrated loads are placed at $a_{v}<2.5 d$ distances, the aggregate interlock has a minor contribution for the shear strength and the load is carried mainly by direct compression struts, which characterizes the compression-shear failure. For loads far from the support, the critical shear crack can usually arise from flexural shear cracks, and the arching action is composed of a combination of direct compression struts (enabled by the aggregate interlock) and elbow-shaped struts (enabled by the tensile strength of concrete) (Muttoni \& Fernandez Ruiz, 2010).

The clear shear span-to-effective depth ratio $a_{v} / d$ has been widely used to reduce design shear force $V_{\text {exp }}$ to take into account the beneficial effect from direct compression struts when a concentrated load is placed close to the support by a factor $\beta$. Therefore, models that do not considerer this shear transfer mechanism tends to be more conservative for reduced values of $a_{v} / d$. Such a ratio, from which compressive struts begin to play an important role, depends on the longitudinal reinforcement ratio, the bond between concrete and reinforcement, but usually varies between 2 and 3 (Kani, 1967; Muttoni \& Fernandez Ruiz, 2010).

\subsection{Overview of available models}

Shear strength models may be divided into semi-empirical, mechanical and purely empirical models (i.e., ANN-based, curve-fitting-based methods and genetic algorithm-based methods (Cladera \& Marí, 2004; Cladera et al., 2014).

Among codes that still use semi-empirical approaches are ABNT NBR 6118:2014 (Brazilian Code) and NEN-EN 1992-1-1:2005 (CEN, 2005). The model provided in the Brazilian code is the same as the CEB Model Code of 1978 (Comité Euro-International du 
Beton (CEB), 1978) and was proposed by Hedman \& Losberg (1978). The model from ACI 318:2014 was developed by MacGregor \& Hanson (1969) - refer to Table 2. Both models were calibrated by regression analyses. Note that the Brazilian model already included the effective depth influence, which was later formalized as the size effect (Bazant \& Kim, 1984). In the Brazilian model, the size effect was derived from statistical treatments with regression analyses. On the other hand, the ACI 318:2014 considered this effect in the detailed formula by including the shear slenderness parameter $M / V d$. The current European code model was first proposed by Regan (Regan, 1987). In this model, $C_{R d, c}$ is an empirical factor used for characteristic shear strength calculations and it was derived from comparison with experimental results and calibrated through reliability analysis on 176 beams tests (Konig \& Fischer, 1995).

ACI 318:2019 (ACI Committee 318, 2019) has incorporated more mechanical parameters in comparison to ACI 318:2014 (ACI Committee 318, 2014), mainly related to the size effect (Kuchma et al., 2019). However, in the present study, both formulations are classified as semi-empirical, since they do not deal directly with the main shear-carrying mechanisms. Owing to improvements in experimental analyses and a better knowledge of the shear strength problem, mechanical models based on different assumptions about what drives shear failure have been proposed.

Model Code 2010 (fib, 2012) has adopted the Simplified Modified Compression Field Thery (SMCFT) as the basis of its formulation (Bentz, Vecchio, \& Collins, 2006) and the Swiss Code SIA 262:2013 (SIA, 2013) has adopted the CSCT model (Muttoni \& Ruiz, 2008) with some simplifications (Muttoni \& Ruiz, 2008). Such models consider the shear capacity as a function of concrete longitudinal strain $\varepsilon$ in a critical section. The MCFT and the CSCT address the shear-transfer mechanisms as a function of a unique parameter and consider both 
aggregate size and concrete compressive strength play an important role in the roughness of the crack, hence, in the aggregate interlock of members subjected to shear.

Other researchers have developed multi-action models that estimate the shear strength by summing the contribution of the main shear transfer mechanisms (Lantsoght, van der Veen, Walraven, \& de Boer, 2015) calculated separately (Marí et al., 2015; Marí, Bairán, Cladera, \& Oller, 2016; Yang et al., 2016). According to the Shear-Flexural Strength Mechanical Model (SFSMM) (Marí et al., 2015, 2016), after the development of the first branch of the critical shear crack, failure takes place when the stresses at any point of the concrete compression chord reach the assumed biaxial stress failure envelope described by Kupfer and Gerstle (1973). In other words, the authors considered failure takes place when the first branch of the critical crack reaches the neutral axis depth, as proposed by Yu et al. (2015). The Compression Chord Capacity Model (CCCM) (Cladera et al., 2016) appears as a simplification of the SFSMM to make it easier to use in daily engineering practice. In CCCM, the authors highlighted that for wide members with a low amount of longitudinal reinforcement and without stirrups, such as one-way slabs, the depth in the uncracked compression zone could be reduced as compared to beams. Therefore, the contribution of the residual tensile stresses for such members can be comparable to the compression chord capacity. In these cases, the CCCM incorporated a minimum shear strength parameter that considerer explicitly the residual tensile stress action to avoid very conservative results.

In the Critical Shear Displacement Theory (CSDT) (Yang et al., 2016, 2017) assumes the critical inclined crack starts from a major flexural crack, which will lead to an overall collapse when the shear displacement $\Delta$ of the crack reaches a critical value and causes a secondary crack (dowel crack) along the reinforcement. According to Yang et al. (2017), a dowel crack causes the detachment of the tensile reinforcement from the concrete along with 
the shear span that significantly reduces the lateral confinement on the crack and the member flexural stiffness. Due to the crack opening in the major crack, an additional vertical shear displacement is required for the recovery of the previous shear stress level in the crack, which feeds the growth of flexural-shear cracks and leads to the brittle collapse of the member.

The Critical Width of a Shear Band model (CWSB) (Tung \& Tue, 2016b, 2016a) focuses on the stress relations just before the critical shear crack formation. According to Tung and Tue (2016a), if the component of normal stress is considered in the tension zone, a shear failure occurs in a shear band when it reaches a critical width value and an inclined crack tends to connect the tips of existing flexural cracks. From this model, the bending moment may have a positive influence on the shear capacity of members such as cantilevers under uniformly distributed loads due to the higher contribution of the compression chord capacity.

Note that for a fair comparison between scientific or mechanical models with design code models, it is important to mention that the second group is usually a simplified version of the first. For instance, the model provided in the Swiss Code SIA 262:2013 (SIA, 2013) is a simplified version of the CSCT (Muttoni \& Ruiz, 2008). Therefore, design code models represent the current knowledge in its date, and they balance factors such as accuracy, precision, safety, and ease of use (Kuchma et al., 2019). In contrast, purely mechanical models focus on the explanation of the shear problem scientifically, with emphasis to the accuracy and precision of its predictions of shear strength.

Table 2, Table 3, Table 4 and Table 5 shows an overview of the aforementioned shear strength models. Table 2 includes design code models derived mainly by statistical treatment (ABNT, 2014; ACI Committee 318, 2014, 2019; CEN, 2005). Table 3 provides design code models derived from mechanical models focused on the capacity of a cracked section to 
transfer shear forces according to the crack opening, named here strain-based models (fib, 2012; SIA, 2013). Table 4 includes mechanical models focused on the compression chord capacity to transfer shear forces, not related to the crack opening (Cladera et al., 2016; Marí et al., 2014). Table 5 shows the formulation of different strain-based models that assumes different parameters to drive the shear failure: (i) the CSDT assumes a critical shear displacement of an existing flexural crack induce the unstable opening of the critical flexural shear crack (Yang et al., 2016) and (ii) the CWSB assumes that the failure takes place when a critical shear crack arises in a shear band when its width reaches a critical value (Tung \& Tue, 2016a). All mechanical models were derived for flexural-shear failures in members with shear slenderness $M / V d>2.5$. All symbols used can be found in the list of notations, and a detailed explanation of some parameters can be consulted in the referred papers. 


\section{Database of experiments}

\subsection{Overview}

The database of wide members under line loads in the member width and under different load arrangements in the span direction contains 170 test results of specimens of $\mathrm{b} / \mathrm{d}$ $>1$ ratio, which is the criterion for the definition of experiments on wide beams and slabs. The tests were conducted by: Adam, Herbrand and Classen (2018), Adam et al. (2019), Adam, Reißen and Hegger (2018), Aster and Koch (1974), Bui et al. (2017), Conforti et al. (2013, 2017) and Conforti et al. (2015), Furuuchi et al. (1998), Ghannoum (1998), Gurutzeaga et al. (2015), Hegger and McGrath (1980), Jäger (2002), Jäger and Marti (2005), Jäger (2007), Kani et al. (1979a), Lantsoght (2013), Leonhardt and Walther (1962), Lubell (2006), Olonisakin and Alexander (1999), Rajagopalan and Ferguson (1968), Reißen (2016) and Serna-Ros et al. (2002).

The database was compiled by Sousa, Lantsoght, \& El Debs (2019) based on a review of the literature and is available in the public domain. This database includes tests performed in different support conditions: (i) 61 on continuous members with different degrees of rotational restraint $d_{r}$, (ii) 92 on simply-supported specimens and (iii) 17 on cantilever members. The database includes 162 tests performed under concentrated loads and just 7 tests under uniformly distributed loads in the shear span (refer to Figure 1a,c). The description of the failure mode in compression-shear failure and flexural shear failure would be interesting to identify members on which direct compressive struts improved the arching action. Furthermore, this classification could help to evaluate more consistently the members with flexural-shear failure, which is the shear failure mode for which were derived most mechanical models. Unfortunately, not all references provide pictures with the cracking pattern of the members, which limited these classifications. However, we can highlight that 
the database includes 94 tests with shear slenderness $M / V d<3$ and 76 tests with shear slenderness $M / V d \geq 3$. Therefore, the number of members which may have presented compression shear failure, due to the influence of direct compressive struts improving the arching action, is slightly higher in this database compared to the members subjected to the flexural-shear failure.

Several references have missing information, such as the support overhang (Ghannoum, 1998; Heger \& McGrath, 1980), maximum diameter of the aggregate (Olonisakin \& Alexander, 1999; Rajagopalan \& Ferguson, 1968), rebar diameter and rebar spacing (Aster and Koch, 1974; Heger and McGrath, 1980; Kani et al., 1979b; Leonhardt and Walther, 1962; Rajagopalan and Ferguson, 1968), and size of the loading and support plates (Aster and Koch, 1974). For tests supported by rollers, the size of support plates was considered $10 \mathrm{~mm}$ (Conforti et al., 2017). Whenever possible, information was taken from the original references. In cases whose geometrical information was not provided in the text, measures were estimated from technical drawings and figures when available.

Concerning concrete compressive strength, $f_{c}$ refers to the average concrete compressive strength measured in cylinders. A 0.85 reduction factor was used for converting the measurements from cubes to cylinders, (Lantsoght, Van Der Veen, \& Walraven, 2013). The sectional shear strength of all tests was calculated towards the elimination of some inconsistencies related or not to the self-weight consideration based on the applied loads and specimen's geometry. As in many cases, the cracking pattern was not reported and the critical shear crack location was not known in these tests. Therefore and towards a uniform analysis, the shear capacity at failure was calculated at $a / 2$ (with $a$ being the shear span) for members under concentrated loads. For those under distributed loads, the shear force at failure was calculated as the shear force at the inner support. 


\subsection{Parameter ranges in database}

Table 6 shows the parameters ranges in the database. According to Table 6, the limitation of thicknesses tested $(<1.01 \mathrm{~m})$ hampers the investigations on the size effect for the collected experiments (ACI Committee 446, 1991; Bazant \& Kim, 1984; Yu et al., 2016). The database includes some experiments with concrete compressive strengths higher than $65 \mathrm{MPa}$, for which the aggregate interlock may make a minor contribution to the shear strength due to the smoother crack surfaces (Fédération Internationale du Béton (fib), 2012). Regarding parameter $a_{v} / d$, as the database includes experiments under concentrated loads with $a_{v} / d<2.5$ ratios, the influence of direct shear force transfer by compressive struts on the shear strength could be investigated.

Figure 8 shows the frequency distribution of the database parameters. According to Figure $8 \mathrm{a}$, most tests were performed in the range of concrete compressive strengths between $25 \mathrm{MPa}$ and $50 \mathrm{MPa}$. Only four tests were performed with $f_{c}>65 \mathrm{MPa}$. As it is typical in shear databases, the longitudinal reinforcement ratio is concentrated in ranges larger than $0.75 \%$ for the avoidance of flexural failure modes (Figure $8 \mathrm{~b}$ ). The small number of tests with effective depths $d$ higher than $600 \mathrm{~mm}$, of major interest for bridge deck slabs, hampers investigations of the size effect on wide members (Figure 8c). Figure 8d shows approximately half of the tests were performed with loads at $a_{v} / d$ ratios lower than 3 , and therefore are influenced by direct shear loads transfer towards the support through compressive struts. Such members may have failed due to concrete crushing in the compression zone, denoted here as shear compression failure (Yang et al., 2017). Since most mechanical models have been formulated for members that show flexural shear failure $(M / V d>2.5-3)$, a higher scattering can be expected between experimental and predicted shear capacities. The parameter of rebar 
spacing-to-effective depth ratio $(s / d)$ in the database shows a concentration of values smaller than 0.8 (Figure 8e).

Figure $8 \mathrm{f}$ shows a reduced number of members with $b / d$ ratios higher than $5(<20 \%)$, which can be related to difficulties in performing tests on large members, whose loads required to reach shear failures can be higher than the actuator capacities. According to the available test results, the effect of member width $b$ on the shear behavior will be evaluated mainly in the range of wide beams, typical of transition members. More test results are required for investigation on the shear behavior of wide members such as one-way slabs. An interesting aspect of this database is the absence of tests under axial loads, for which is supposed the same behavior of beams. 


\section{Results}

\subsection{Parameter analyses on the shear strength of $\mathrm{RC}$ wide members}

The tensile strength of concrete plays an important role in the shear behavior of RC members since it controls the crack widths and the ability of transfer shear forces (ASCEACI Committee 445, 1998). However, in design, it is more usual to specify the concrete compressive strength and correlate it with the concrete tensile strength. The Eurocode (CEN, 2005) correlates the tensile strength of concrete with $f_{c}^{1 / 3}$, whereas Model Code 2010 (fib, 2012) and SIA code (SIA, 2013) adopt relations with $f_{c}^{1 / 2}$. In the Brazilian code (ABNT, 2014), the concrete tensile strength is estimated by a relation with $f_{c}^{2 / 3}$. Towards an evaluation of which of the relations that best fits the tensile strength of concrete and a comparison between different groups of tests, the shear capacity $V_{\exp }$ was normalized with $b$ and $d$ for finding the shear stress and further normalized with $f_{c}^{1 / 3}$ and $f_{c}^{1 / 2}$ for determining the normalization for the compressive strength that leads to the most uniform results.

Figure 9 shows the shear strength of wide members normalized by the geometry of the section $\left(b\right.$ and $d$ ) and $f_{c}^{1 / 2}$ seems the most appropriate, since it provided the smallest inclination of the trendline (Figure 9a). Therefore, we used the normalized shear strength by $f_{c}^{1 / 2}$ in the parameter analysis (Figure 10). On the other hand, differences of tendency caused by the use of $f_{c}^{1 / 2}, f_{c}^{1 / 3}$ and $f_{c}^{2 / 3}$ can be negligible.

Figure 10 shows the influence of the parameters evaluated on normalized shear strength. The inclination of the trendlines indicates a higher or lower influence of the parameter evaluated on the normalized shear strength. In Figure 10c the data points referred to members under distributed loads are not shown since, for these members, we can not define the ratio $a_{v} / d$. For Figure 10e the point with higher normalized shear strength, as well as other data points, were not plotted due to the reference not cite the spacing between rebars for some 
members. Table 7 shows the main observations displayed in Figure 10 regarding the influence of parameters related to material, geometry, reinforcement, and load-layout in the shear strength.

\subsection{Shear slenderness}

Some studies have indicated a good correlation between the shear slenderness and the shear strength of beams and wide members for members subjected to concentrated loads (CL) (Adam, Herbrand, et al., 2018; Yang et al., 2017). We performed an evaluation of shear slenderness definition which includes continuous members under uniformly distributed loads (DL). The shear slenderness definition used by Adam et al. (2019), which considers only the location of the point of inflection, was compared with the one showed in Table 1, which accounts for moments $M_{\text {sup }}$ and $M_{\text {span }}$. The normalized shear strength of the database (170 tests), more 19 tests almost loaded in the full width from Lantsoght (2013) and Reißen (2016), was evaluated and only tests with an exclusive variation of the analyzed parameter remained. Figure 11a shows a good correlation of normalized shear strength with the ratio $\max \left(a_{1} ; a_{2}\right) / d$ for wide members under concentrated loads (CL). However, the behavior under uniformly distributed loads (DL) does not show the same clear tendency. In Figure 11a, the shear strength of members under DL increases in the initial range of $\max \left(a_{1} ; a_{2}\right) / d$, however, it decreases in the last range.

Some of the data points which refer to tests under DL were related to continuous members with $M_{\text {sup }}<M_{\text {span }}$, for which we propose calculating the shear slenderness assuming they are simply supported ones of reduced span length (Figure 5 and Table 1). We observe a better correlation of the shear strength with $\max \left\{a_{1} ; a_{2}\right\} / d$ ratio (Figure $11 \mathrm{~b}$ ), and similar behavior in comparison to members under CL. This result agrees with most studies on beams, 
in which a higher $\max \left\{a_{1} ; a_{2}\right\} / d$ leads to wider flexural cracks under the same loads, hence, a lower shear resistance (Yang et al., 2017). This relation is more evident and was validated by experimental measurements for structural members and load arrangements whose aggregate interlock is the main shear-carrying mechanism in the cracked section (Campana, Ruiz, Anastasi, \& Muttoni, 2013).

Another aspect usually neglected in experimental analyses of beams and wide members (Gurutzeaga et al., 2015; Lantsoght et al., 2015) is the effect of the degree of rotational restraint $d_{r}$ of continuous members in the internal support. Reißen (2016) reported some results limited to members under concentrated loads (CL). Figure 12 shows the behavior of continuous members according to the degree of rotational restraint is more heterogeneous in comparison with the shear slenderness (Figure 11b). However, we identified some tendencies in the relation between shear capacity and $d_{r}$ according to the shear slenderness parameter, shown in Table 8.

\subsection{Comparison to semi-empirical and mechanical model predictions}

The experimental shear strength of 170 tests was compared with the one provided by the following semi-empirical and mechanical models: (i) ABNT NBR 6118:2014 (Brazilian Code), (ii) NEN 1992-1-1:2005 (CEN, 2005), (iii) ACI 318:2014 (ACI Committee 318, 2014), (iv) ACI 318:2019 (ACI Committee 318, 2019), (v) Model Code 2010 (fib, 2012), (vi) SIA 262:2013 (SIA, 2013), (vii) Shear Flexural Strength Mechanical Model (SFSSM) (Marí et al., 2015), (viii) Compression Chord Capacity Model (CCCM) (Antoni Cladera et al., 2016), (ix) the Critical Shear Displacement Theory CSDT (Yang et al., 2016) and (x) Critical Width of the Shear Band Theory (CWSB) (Tung \& Tue, 2016a). The next sections address evaluations of the ratio between experimental and theoretical shear strengths according to the structural system, $b / d$ ratio and shear slenderness. 
For small values of $a_{v} / d$, an arching action leads to larger shear capacities, consequently, models that do not take this aspect into account tend to produce more conservative results for members whose concentrated loads are close to the support. However, in most studies, such conservatism is not quantified for wide RC members. Some mechanicalbased models, such as SIA 262 (SIA, 2013) and fib Model Code 2010 (fib, 2012) provide guidance on how to consider the effects of direct compression struts carrying the shear force to the supports. Other models, (e.g., SFSMM (Marí et al., 2015), CCCM ( Cladera et al., 2016), CSDT (Yang et al., 2016) and CWSB (Tung \& Tue, 2016a), do not include such guidance. In such cases, the factor $\beta_{\mathrm{EC}}$ from NEN 1991-1-1:2005 (CEN, 2005) is considered for reducing $V_{\text {exp }}$ for evaluations of the fit of the mechanical models. Items 4.3.2 and 4.3.3, show only the results from mechanical-based models, since they provided better accuracy and precision in the shear strength predictions.

\subsubsection{Accuracy according to the structural system}

The effect of the structural system on the shear behavior is usually neglected. Towards investigating it, we compared experimental and predicted shear capacities according to the different structural systems of the tests by different models. Statistical trends can influence the results, since the number of tests in the databases for simply supported specimens $(67 \%)$ is significantly higher than those for continuous members $(23 \%)$ and cantilever ones $(10 \%)$. Therefore, the results of this section should be considered as indicative and more tests are necessary for reliable conclusions.

The ratio between experimental and calculated shear strengths $V_{\text {exp }} / V_{c a l}$ by semiempirical models showed a coefficient of variation (COV) higher than $25 \%$ for all models (Table 9). The structural system provided the lowest average ratio $V_{\text {exp }} / V_{\text {cal }}$ for cantilever members (CT) by the semi-empirical approaches. Table 9 also shows semi-empirical approaches overestimate shear predictions between $28 \%$ and $102 \%$ for continuous wide 
members. Physically, most of such results can be explained by the absence of parameters that consider the shear slenderness effect, proven by the smallest difference in results between simply supported and continuous members in the detailed model of ACI 318:2014. However, the $V_{\text {exp }} / V_{\text {cal }}$ ratio is in ACI 318:2014 approximately 25\% higher for simply supported members than for cantilever ones.

Most mechanical models of shear strength consider the structural system indirectly by parameters related to the sectional forces $M$ and $V$, which are correlated to the shear slenderness. Nevertheless, the $V_{\text {exp }} / V_{\text {cal }}$ ratio for continuous members was higher than that for simply supported members by all mechanical models (Table 10). This difference is limited (10\%) with SIA 262 and the CSDT formulations. Table 10 shows the $V_{\text {exp }} / V_{\text {cal }}$ ratio for cantilever members is lower than for simply supported ones by all models, except for CSDT, whose difference can be neglected. Such results suggest if the structural system is considered only by the sectional forces $M$ and $V$, possible changes in the main shear-carrying mechanisms may be neglected due to alterations in the shear failure mode and cracking pattern according to the moments $M_{\text {sup }}$ and $M_{\text {span }}$.

In most validations of mechanical-based models with beam tests, a comparison between the proposed models with semi-empirical approaches highlighted better accuracy and precision with mechanical based models (Marí et al., 2015; Tung \& Tue, 2016a; Yang et al., 2016). In a joint assessment of average value and coefficient of variation of all models, SIA 262:2013 (SIA, 2013) and CSDT models (Yang et al., 2016, 2017) stand out with the average ratio $V_{\text {exp }} / V_{\text {calc }}$ ranging between 1.13 and 1.15 and COVs lower than 20\%. Equations based on the SFSMM (Marí et al., 2015), CCCM (Cladera et al., 2016) and CWSB (Tung \& Tue, 2016a), provided larger scatter between experimental and predicted capacities (COV > 20\%). These results are caused by including members in the database that may have failed by shear 
compression modes, for which these models were not derived. The same models (CCCM, SFSMM and CWSB) showed an average ratio $V_{\text {exp }} / V_{\text {cal }}$ between 0.99 and 1.16 with maximum COV of $15.8 \%$ for wide RC members that showed flexural shear failure modes, identified as those of $M / V d>3$ (76 test results in the databases).

\subsubsection{Accuracy according to the b/d ratio}

The experimental shear capacities were compared with predicted ones according to different ranges of $b / d$ ratios for investigating whether the available shear models show the same level of accuracy regardless of the ratio $b / d$. According to Table 11 , the mechanical models show no significant differences in the mean value and COV for $V_{\text {exp }} / V_{\text {cal }}$ in the different $b / d$ ratio ranges. Although the coefficient of variation showed higher values in the range $1<b / d<2.5$, this result may have been influenced by the higher number of experiments in this range ( $63 \%$ of the tests). Such results agree with the experimental analysis conducted by Adam et al. (2018), who observed slabs with $b / d>5$ and beams with $b / d=1$ exhibited similar shear capacities under identical test conditions. The results are also coherent with the observation that the influence of $b / d$ on the normalized shear strength is limited (Figure 10f). On the other hand, they do not validate the observations of Conforti et al. (2017), who found higher shear strengths for increasing $b / d$ ratios between 1 and 3. Therefore, the effect of the $b / d$ ratio on the shear strength is still unclear and closely related to the randomness in the cracking pattern of the model, concrete mixture's homogeneity and loading conditions.

\subsubsection{Accuracy according to the shear slenderness $\lambda$}

Most mechanical models have been formulated to deal with flexural shear failures. Table 12 shows the similarity among the results provided by mechanical models for tests with flexural shear failure $(\lambda \geq 3)$. The average ratio between experimental and predicted shear capacities ranged from 0.99 to 1.16 , whereas the coefficient of variation remained below $20 \%$. For members with possible shear compression failure, the coefficient of variation for $V_{\text {exp,red }} / V_{\text {cal }}$ 
ratio is higher than $20 \%$ for models based on the CCCM and in the CWSB. However, such models provide more conservative results for most of these tests since the average $V_{\text {exp,red }} / V_{\text {cal }}$ ratio is higher than 1.24 for them.

\section{Discussions}

Most semi-empirical approaches used in codes of practice did not consider the shear slenderness influence and were calibrated according to slender simply supported beam tests (ABNT, 2014; ACI Committee 318, 2019; CEN, 2005). Therefore, these formulations could provide very conservative capacities for small shear slenderness, as verified with the ACI 318:2019 model for continuous members (refer to the average ratio $V_{\text {exp }} / V_{A C l, 319(c)}=2.024$ in Table 9), and provide unsafe predictions for higher member thicknesses (refer to the minimum value $V_{\text {exp }} / V_{A B N T}=0.558$ in Table 9).

Figure 10 shows that the longitudinal reinforcement ratio $\rho_{l}$, the effective depth $d$ and the shear slenderness $M / V d$ have a higher influence on the shear strength than parameters such as the ratio $b / d$ and the ratio $s / d$ in the investigated ranges. The longitudinal reinforcement ratio acts in two ways for strain-based models: (i) increasing the stiffness to crack opening (Muttoni \& Ruiz, 2008) and (ii) improving the contribution of the dowel action (Yang et al., 2016). In models based on the compression chord capacity (Cladera et al., 2016; Marí et al., 2014), higher longitudinal reinforcement ratios increase the compression chord dimension $x$ and allow reaching higher normal stress in the compression chord (Tung \& Tue, 2016a). These two effects improve the capacity of transfer shear forces through the uncracked concrete zone. The increase in the effective depth of the longitudinal reinforcement $d$ or in the shear slenderness $M / V d$ has a similar negative effect on the shear strength of members without stirrups, since they induce higher crack openings for the same level of load. Since for strainbased models, the increase in the crack opening reduces the contributions of the aggregate 
interlock, reduced shear capacities may be expected for these members, as verified in Figure 10b,d and in Figure 11. In models based in compression chord capacity, instead, the reduction of the shear capacity increasing the shear slenderness of effective depth $d$ is explained due the empirical factors such as the $\zeta$ ( Cladera et al., 2016) or by accounting the reduced dimension of the shear band in the CWSB (Tung \& Tue, 2016a).

This physical background explains the higher and similar level of accuracy and precision of the studied mechanical-based models in Table 12 for members with shear slenderness $\lambda \geq 3$, despite these models being derived in different ways. Note that all models showed an average ratio of $V_{\text {exp }} / V_{\text {cal }}$ that deviates from 1 by less than $20 \%$, while the coefficient of variation remains reduced (around 15\%) for all models. In the range of shear slenderness $\lambda<3$ some models showed a coefficient of variation higher than $20 \%$, despite using a factor for reducing the acting shear load in this range to account for direct compressive struts providing arching action. At this point, it should be remembered that most mechanical models were not derived for shear slenderness lower than 2.5 , since these members are most subjected to compression shear failures. Therefore, it is reasonable that these models provide a higher scatter between predicted and experimental shear capacities in this range. At the same time, some authors (Sagaseta \& Vollum, 2010; Vollum \& Fang, 2015) could question if this approach is correct since strut-and-tie models can also represent the behavior of these members. Hence, these results may be interpreted as a first approach to asses the level of accuracy of these mechanical models in a simplified manner, as allowed in other design code models such as Model Code 2010 and NEN 1992-1-1:2005.

According to Figure 10 and Table 11, there is no significant sensibility in the shear strength of wide members according to the ratio $b / d$. Hence, we may not state that models of shear strength derived from beam-shaped tests are more conservative for wide members. In 
tests from which benefits to the shear strength of wide members was found owing to higher cracked surfaces (Conforti et al., 2017), that activated a higher aggregate interlock, the cause of the large areas of cracked surfaces was still not consistently explained.

A closer look at the database shows most of the tests available were performed on simply supported members of small thicknesses under concentrated loads. The investigation of the size effect, structural system and load arrangement influence on the shear strength require more tests. Due to the size effect, the testing of full-scale wide members is important. Since these members are complex and costly, 3D non-linear numerical simulations can be useful (Belletti et al., 2014; Genikomsou \& Polak, 2015). The small number of tests on wide members under distributed loads hampers the drawing of conclusions on the influence of parameters like the degree of rotational restraint $d_{r}$. More tests and a combination of experimental results with numerical simulations are required for more comprehensive analyses. A limited number of tests on wide members of concrete compressive strengths higher than $65 \mathrm{MPa}$ is available and the results have significantly varied, which requires more tests. Such tests will enable evaluations of the accuracy and precision levels of formulations that take into account the lower roughness for crack surfaces when the critical shear crack goes through the aggregate particles.

The shear slenderness based on the $\max \left(a_{1} ; a_{2}\right) / d$ ratio shows a clear correlation with the shear strength of wide members under concentrated loads. We identified a similar correlation for members under uniformly distributed loads by modifying the span length of continuous members according to the relation between the moment over the support $\left(M_{\text {sup }}\right)$ and the maximum moment in the span $\left(M_{\text {span }}\right)$. 


\section{Conclusions}

This paper brings together 170 test results of wide RC members without shear reinforcement and analyzes some of the main semi-empirical and mechanical models available in design codes. It also addresses a discussion on the effect of parameters such as structural system and shear slenderness and a comparison between experimental and predicted shear capacities according to different models. The following conclusions can be drawn:

- Despite some differences in the cracking pattern between beams and wide members for some tests, it was not found a significative influence of the ratio $b / d$ in the shear strength of wide members in the parameter analyses. Therefore, the test of beamshaped members may represent one-way slabs and wide beams. This recommendation is sustained by the lower influence of the ratio $b / d$ compared to other parameters as the shear slenderness $\lambda$, reinforcement ratio $\rho_{l}$ and size effect $d$ (Figure 10 and Table 11).

- An increase in the ratio $\max \left(a_{1} ; a_{2}\right) / d$ results in a clear exponential decay of the shear strength to members under concentrated loads (CL) in the shear span. For members under uniformly distributed loads (DL), the shear strength also decreased by considering that continuous members under distributed loads with $M_{\text {sup }}<M_{\text {span }}$ behave similarly to simply supported ones.

- The shear strength establishes a better correlation with the shear slenderness than with the degree of rotational restraint $d_{r}$. While the shear strength mostly reduces with increasing the shear slenderness, the relation between the shear strength and the degree of rotational restraint is more complex.

- Most models provide less conservative results for cantilevers members than simple supported ones. Although this result might indicate some influence of the structural system, the database shows a higher number of tests with simply-supported members, 
which may add some bias to the results. Furthermore, most results are related to members of reduced thickness $(<0.5 \mathrm{~m})$, for which the self-weight load is reduced; therefore, differences according to the structural system should be limited.

- The Critical Shear Crack Theory (CSCT), adopted in the Swiss Code SIA 262:2013, and the Critical Shear Displacement Theory (CSDT), provide consistent predictions of shear strength for wide members under different structural systems, load arrangements and shear slenderness. In this study, these models show a small COV $(<20 \%)$ and an average ratio $V_{\text {exp }} / V_{\text {pred }}$ between 1.13 and 1.15 , including slender and non-slender members in the analyses. For non-slender members, the reduction of the acting shear load in the critical section with the $\beta$ factor from NEN 1992-1-1:2005 combined with the CSDT model provides accurate results.

- Aspects such as direct load transfer by compressive struts, improvement in the compression chord by continuity at the supports, and load arrangement effect are usually neglected in design with semi-empirical design models. However, they can be important for the assessment of existing structures, since they can considerer additional strength to the structure, such a way that repair or replacement of these structures may be avoided in unnecessary conditions.

\section{Acknowledgments}

The authors gratefully acknowledge the financial support provided by the National Council for Scientific and Technological Development (CNPq) and the São Paulo Research Foundation (FAPESP - 2018/21573-2). We also appreciate the contributions of Angela Pregnolato Giampedro for the English review and the peer-reviewers for their suggestions for the text. 


\section{Notation}

\begin{tabular}{|c|c|}
\hline Notation & Description \\
\hline$a$ & $\begin{array}{l}\text { shear span: the distance between the center of the support and the center of the } \\
\text { load }\end{array}$ \\
\hline$a_{v}$ & clear shear span: the distance between the face of support and face of load \\
\hline$b$ & width of the structural member \\
\hline$b_{n}$ & the clear width of the structural member \\
\hline$d$ & effective depth to main tension reinforcement \\
\hline$d_{l}$ & effective depth towards longitudinal steel \\
\hline$d_{t}$ & effective depth towards transverse steel \\
\hline$d_{\max }$ & maximum aggregate size \\
\hline$d_{g}$ & maximum aggregate size \\
\hline$d_{0}$ & effective depth $d$, but not less than $100 \mathrm{~mm}$ (CI 2017) \\
\hline$d_{b, c r i t}$ & critical width of the shear band (CWSB) \\
\hline$f_{c}$ & concrete compressive strength \\
\hline$f_{c k}$ & characteristic concrete compressive strength \\
\hline$f_{c m}$ & mean value of the cylinder concrete compressive \\
\hline$f_{c t m}$ & mean value of the concrete tensile strength \\
\hline$f_{c t d}$ & the design value of the concrete tensile strength \\
\hline$f_{c t k, i n f}$ & tensile strength of the concrete in the lower quantile \\
\hline$f_{y}$ & yield strength of reinforcement \\
\hline$k_{1}$ & $\begin{array}{l}\text { coefficient considering the effects of axial forces on the stress distribution ( } 0.15 \\
\text { in the European code to one-way shear) }\end{array}$ \\
\hline$k_{E C}$ & factor taking into account the size effect according to NEN -EN 1992-1-1:2005 \\
\hline$k_{N B R}$ & factor taking into account the size effect according to ABNT NBR 6118:2014 \\
\hline$k_{c}$ & slope of stress line, $k_{c}=1.28$ according to (Krips, 1985) \\
\hline$k_{d}$ & factor determining the shear capacity in the Swiss Code SIA 262:2013 \\
\hline$k_{d g}$ & factor for accounting for the aggregate size $d_{g}$ in Model Code 2010 \\
\hline$k_{g}$ & factor for accounting for the aggregate size $d_{g}$ in the Swiss code SIA 262:2013 \\
\hline$k_{v}$ & factor accounting for strain effect and member size in the fib Model Code 2010 \\
\hline$m_{E d}$ & design (factored) moment per unit length in critical section \\
\hline$m_{R d}$ & plastic design (factored) moment per unit length in critical section \\
\hline$n_{e}$ or $n$ & ratio between elastic modulus of steel and concrete \\
\hline$l_{c r, m}$ & spacing of two neighboring major cracks \\
\hline$S_{c r, C S D T}$ & height of fully developed crack \\
\hline$S_{c r, S f s m m}$ & location of the section where the critical shear crack starts \\
\hline$s_{u}$ & location of the critical shear section \\
\hline$S_{r m}$ & crack spacing of primary cracks \\
\hline$v_{c}$ & $\begin{array}{l}\text { dimensionless contribution to the shear strength of the un-cracked concrete } \\
\text { chord }\end{array}$ \\
\hline$v_{l}$ & $\begin{array}{l}\text { dimensionless contribution to the shear strength of the longitudinal } \\
\text { reinforcement }\end{array}$ \\
\hline$v_{S}$ & dimensionless contribution to the shear strength of the transverse reinforcement \\
\hline$w$ & crack width \\
\hline$w_{b}$ & crack width at the bottom of the crack \\
\hline$w_{k}$ & Crack opening of the primary cracks (CWSB) \\
\hline
\end{tabular}




\begin{tabular}{|c|c|}
\hline$w_{1}$ & Crack opening to zero tensile stress of the concrete \\
\hline$x$ & neutral axis depth \\
\hline$x^{\prime}$ & distance from the peak of the concrete tensile stress to the neutral axis (CWSB) \\
\hline$x^{\prime \prime}$ & height of the region with softening of concrete in the tension zone (CWSB) \\
\hline$x_{0}$ & distance from the critical shear crack to the support or loaded area CWSB) \\
\hline$x_{1}$ & distance from the control section to the support or loaded area (CWSB) \\
\hline$z$ & $\begin{array}{l}\text { length of the internal level arm or effective shear depth according to fib } \mathrm{MC} \\
2010 \text {, can be taken as } 0.9 d\end{array}$ \\
\hline$z_{c}$ & depth of concrete compression zone \\
\hline$A_{x}, A_{y}$ & projected areas of a cracked surface for a unit crack length in two directions \\
\hline$A_{S}$ & longitudinal reinforcement area \\
\hline$A_{s w}$ & area per unit length of the transverse reinforcement \\
\hline$A_{g}$ & gross area of concrete section \\
\hline$C_{R d, c}$ & regression coefficient in Eurocode shear formula \\
\hline$E_{c}$ & modulus of elasticity of concrete \\
\hline$E_{S}$ & elastic modulus of steel \\
\hline$G_{c}$ & modulus of shear deformation for the un-cracked concrete chord \\
\hline$G_{f}$ & concrete fracture energy \\
\hline$M$ & cross-sectional bending moment \\
\hline$M_{c r}$ & cracking moment \\
\hline$M_{E d}$ & design sectional moment \\
\hline$M_{\max }$ & maximum bending moment of the shear span (CWSB) \\
\hline$N_{E d}$ & design sectional axial load \\
\hline$V$ & shear force \\
\hline$V_{a i}$ & shear force transferred by aggregate interlock \\
\hline$V_{c}$ & shear force transferred in concrete compression zone \\
\hline$V_{d}$ & shear force transferred by dowel action \\
\hline$V_{E d}$ & design shear force \\
\hline$V_{\exp }$ & Experimental shear force strength from the database tests \\
\hline$V_{c a l}$ & Calculated shear force strength \\
\hline$V_{N B}$ & shear capacity calculated according to ABNT NBR 6118:2014 \\
\hline$V_{E C}$ & shear capacity calculated according to EN 1992-1-1:2005 (EC) \\
\hline$V_{A C I-14}$ & shear capacity calculated according to ACI $318-14$ \\
\hline$V_{A C I-19}$ & shear capacity calculated according to ACI 318-19 \\
\hline$V_{M C}$ & shear capacity calculated according to Model Code 2010 \\
\hline$V_{S I A}$ & shear capacity calculated according to SIA $262: 2013$ \\
\hline$V_{\text {SFSMM }}$ & shear capacity calculated according to SFSMM \\
\hline$V_{C C C M}$ & shear capacity calculated according to CCCM \\
\hline$V_{C S D T}$ & shear capacity calculated according to CSDT \\
\hline$V_{C W S B}$ & Shear capacity calculated according to CWSB \\
\hline$\alpha_{e}$ & modular ratio $\left(E_{s} / E_{c}\right)$ \\
\hline$\beta$ & $\begin{array}{l}\text { reduction factor for the contribution of loads close to the support to the shear } \\
\text { force at the support }\end{array}$ \\
\hline$\gamma_{\mathrm{c}}$ & partial safety factor for concrete \\
\hline$\Delta$ & shear displacement at crack \\
\hline$\Delta_{c r}$ & critical shear displacement \\
\hline$\Delta_{e}$ & distance between neutral axis and center of internal lever arm $\mathrm{z}$ \\
\hline
\end{tabular}




\begin{tabular}{|c|c|}
\hline$\varepsilon_{x}$ & the longitudinal strain at mid-depth of the effective shear depth \\
\hline$\varepsilon_{c t}$ & Strain of concrete by reaching the tensile strength (CWSB) \\
\hline$\lambda$ & $\begin{array}{l}\text { modification factor reflecting the reduced mechanical properties of lightweight } \\
\text { concrete in the ACI } 318: 2019 \text { or shear slenderness }\end{array}$ \\
\hline$\lambda_{\mathrm{s}}$ & Size effect modification factor on ACI 318:2019 \\
\hline$\phi$ & rebar diameter \\
\hline$\phi_{\text {eq }}$ & equivalent rebar diameter \\
\hline$\zeta$ & combined size effect and slenderness factor on SFSMM and CCCM \\
\hline$\mu, C S D T$ & $\begin{array}{l}\text { friction coefficient for contact area between aggregate particles and matrix, with } \\
\text { a proposed value } \mu=0.4 \text { according to Walraven (J. C. Walraven, 1980) }\end{array}$ \\
\hline$\mu$, Sfsmm & dimensionless bending moment $\left(M /\left(f_{c t} \cdot b \cdot d\right)\right)$ \\
\hline$\xi$ & dimensionless neutral axis depth \\
\hline$\rho_{s}$ & longitudinal reinforcement ratio \\
\hline$\rho_{\rho, e f f}$ & $\begin{array}{l}\text { reinforcement ratio in the effective area of concrete surrounding the } \\
\text { reinforcement }\end{array}$ \\
\hline$\sigma$ & normal stress \\
\hline$\sigma_{c p}$ & $\begin{array}{l}\text { average normal concrete stress over the cross-section, positive in compression } \\
\text { (Brazilian code) }\end{array}$ \\
\hline$\sigma_{p u}$ & crushing (yielding) strength of matrix, or contact stress at cracked surface \\
\hline$\sigma_{x m}$ & $\begin{array}{l}\text { average normal stress of concrete within the critical width of the shear band } \\
\text { (CWSB) }\end{array}$ \\
\hline$\tau$ & shear stress \\
\hline$\tau_{a i}$ & shear stress transferred by aggregate interlock \\
\hline$\tau_{R d}$ & design shear capacity of the concrete \\
\hline$\tau_{R c}$ & relative shear capacity, $\tau_{R c}=V_{R c} /(b d)(\mathrm{CWSB})$ \\
\hline$\tau_{c}$ & concrete shear capacity \\
\hline$\tau_{\max }$ & maximum shear stress at the neutral axis (CWSB) \\
\hline$\tau_{u}$ & Allowable shear stress in the critical width of the shear band (CWSB) \\
\hline AVG & Average value \\
\hline $\mathrm{COV}$ & coefficient of variation \\
\hline CSCT & Critical Shear Crack Theory \\
\hline CSDT & Critical Shear Displacement Theory \\
\hline CWSB & Critical Width of the Shear Band \\
\hline CCCM & Compression Chord Capacity Model \\
\hline SFSMM & Shear Flexure Strength Mechanical Model \\
\hline MCFT & Modified Compression Field Theory \\
\hline MIN & Minimum value \\
\hline
\end{tabular}




\section{References}

ABNT. NBR 6118: Projeto de Estruturas de Concreto - Procedimento. , (2014).

ACI-ASCE Committee 326. (1962a). Shear and Diagonal Tension. ACI Journal Proceedings, 59(2), 277-334. https://doi.org/10.14359/7920

ACI-ASCE Committee 326. (1962b). Shear and Diagonal Tension. ACI Journal Proceedings, 59(3), 353-396. https://doi.org/10.14359/7921

ACI-ASCE Committee 326. (1962c). Shear and Diagonal Tension. ACI Journal Proceedings, 59(1), 1-30. https://doi.org/10.14359/7913

ACI Committee 318. (2014). Building Code Requirements for Structural Concrete (ACI 318-14) and Commentary (Vol. 11, p. 6858). Vol. 11, p. 6858. American Concrete Institute, Farmington Hills, MI.

ACI Committee 318. (2019). Building Code Requirements for Structural Concrete (ACI 318-19) (p. 988). p. 988. American Concrete Institute, Farmington Hills, MI.

ACI Committee 446. (1991). Fracture Mechanics of Concrete: Concepts, Models and Determination of Material Properties. ACI 446.1 R-91 (Reapproved 1999), American Concrete Institute, 1-146.

Adam, V., Classen, M., Hillebrand, M., \& Hegger, J. (2019). Shear in continuous slab segments without shear reinforcement under distributed loads. Proceedings of the Fib Symposium 2019 - Concrete - Innovations in Materials, Design and Structures, (Dbv 2013).

Adam, V., Herbrand, M., \& Claßen, M. (2018). Experimentelle Untersuchungen zum Einfluss der Bauteilbreite und der Schubschlankheit auf die Querkrafttragfähigkeit von Stahlbetonplatten ohne Querkraftbewehrung. Bauingenieur, 93(January).

Adam, V., Reissen, K., \& Hegger, J. (2018). Influence of support conditions on shear in RC members without shear reinforcement. In D. A. Hordijk \& M. Luković (Eds.), High Tech Concrete: Where Technology and Engineering Meet - Proceedings of the 2017 fib Symposium. https://doi.org/10.1007/978-3-319-59471-2

ASCE-ACI Committee 445. (1998). Recent Approaches to Shear Designof Structural Concrete. Journal of Structural Engineering, 124(12), 1375-1417.

Aster, H.; Koch, R. (1974). Shear capacity of deep concrete slabs. Beton- Und Stahlbetonbau, 69(11), 266-270.

Bazant, Z. P., \& Kim, J.-K. (1984). Size Effect in Shear Failure of Longitudinally Reinforced Beams. ACI Journal Proceedings, 81(5), 456-468. https://doi.org/10.14359/10696

Belletti, B., Damoni, C., Hendriks, M. A. N., \& De Boer, A. (2014). Analytical and numerical evaluation of the design shear resistance of reinforced concrete slabs. Structural Concrete, 15(3), 317-330. https://doi.org/10.1002/suco.201300069

Bentz, E. C., Vecchio, F. J., \& Collins, M. P. (2006). Simplified modified compression 
field theory for calculating shear strength of reinforced concrete elements. $A C I$ Structural Journal, 103(4), 614-624. https://doi.org/10.14359/16438

Bui, T. T., Limam, A., Nana, W.-S.-A., Ferrier, E., Bost, M., \& Bui, Q.-B. (2017). Evaluation of one-way shear behaviour of reinforced concrete slabs: experimental and numerical analysis. European Journal of Environmental and Civil Engineering, (September), 1-27. https://doi.org/10.1080/19648189.2017.1371646

Caldentey, A. P., Padilla, P., Muttoni, A., \& Ruiz, M. F. (2012). Effect of load distribution and variable depth on shear resistance of slender beams without stirrups. ACI Structural Journal, 109(5), 595-603.

Calvi, P. M., Bentz, E. C., \& Collins, M. P. (2018). Model for assessment of cracked reinforced concrete membrane elements subjected to shear and axial loads. $A C I$ Structural Journal, 115(2), 501-509. https://doi.org/10.14359/51701093

Campana, S., Ruiz, M. F., Anastasi, A., \& Muttoni, A. (2013). Analysis of sheartransfer actions on one-way RC members based on measured cracking pattern and failure kinematics. Magazine of Concrete Research, 65(6), 386-404. https://doi.org/10.1680/macr.12.00142

Cavagnis, F., Fernández Ruiz, M., \& Muttoni, A. (2015). Shear failures in reinforced concrete members without transverse reinforcement: An analysis of the critical shear crack development on the basis of test results. Engineering Structures, 103, 157-173. https://doi.org/10.1016/j.engstruct.2015.09.015

Cavagnis, F., Fernández Ruiz, M., \& Muttoni, A. (2018). An analysis of the sheartransfer actions in reinforced concrete members without transverse reinforcement based on refined experimental measurements. Structural Concrete, 19(1), 49-64. https://doi.org/10.1002/suco.201700145

CEN. (2005). EN 1992-1-1: Eurocode 2: Design of concrete structures -Part 1-1: General rules and rules for buildings, EN 1992-1-1:2005. Comité Européen de Normalisation, Brussels, Belgium.

Chana, P. S. (1987). Investigation of the mechanism of shear failure of reinforced concrete beams. Magazine of Concrete Research, 39(141), 196-204. https://doi.org/10.1680/macr.1987.39.141.196

Cladera, A, \& Marí, A. R. (2004). Shear design procedure for reinforced normal and high-strength concrete beams using artificial neural networks. Part I: beams without stirrups. Engineering Structures, 26, 917-926. https://doi.org/10.1016/j.engstruct.2004.02.010

Cladera, Antoni, Marí, A., Bairán, J. M., Ribas, C., Oller, E., \& Duarte, N. (2016). The compression chord capacity model for the shear design and assessment of reinforced and prestressed concrete beams. Structural Concrete, 17(6), 1017-1032. https://doi.org/10.1002/suco.201500214

Cladera, Antoni, Pérez-Ordóñez, J. L., \& Martínez-Abella, F. (2014). Shear strength of $\mathrm{RC}$ beams. Precision, accuracy, safety and simplicity using genetic programming. Computers and Concrete, 14(4), 479-501. https://doi.org/10.12989/cac.2014.14.4.479 
Comité Euro-International du Beton (CEB). (1978). Shear and torsion, June:

Explanatory and viewpoint papers on Model Code Chapters 11 and 12, prepared by CEB Committee V. In CEB Bulletin d'Information no. 126. Paris: Comité EuroInternational du Beton.

Conforti, A., Minelli, F., \& Plizzari, G. A. (2013). Wide-shallow beams with and without steel fibres: A peculiar behaviour in shear and flexure. Composites Part B: Engineering, 51, 282-290. https://doi.org/10.1016/j.compositesb.2013.03.033

Conforti, A., Minelli, F., \& Plizzari, G. A. (2017). Influence of width-to-effective depth ratio on shear strength of reinforced concrete elements without web reinforcement. ACI Structural Journal, 114(4), 995-1006. https://doi.org/10.14359/51689681

Conforti, A., Minelli, F., Tinini, A., \& Plizzari, G. A. (2015). Influence of polypropylene fibre reinforcement and width-to-effective depth ratio in wideshallow beams. Engineering Structures, 88, 12-21. https://doi.org/10.1016/j.engstruct.2015.01.037

Fédération Internationale du Béton (fib). (2012). fib Model Code for Concrete Structures 2010. Ernst \& Sohn - fédération internationale du béton, Bulletin 65, Lausanne, Switzerland.

Fernández Ruiz, M., Zanuy, C., Natário, F., Gallego, J. M., Albajar, L., \& Muttoni, A. (2015). Influence of Fatigue Loading in Shear Failures of Reinforced Concrete Members without Transverse Reinforcement. Journal of Advanced Concrete Technology, 13(5), 263-274. https://doi.org/10.3151/jact.13.263

Furuuchi, H., Takahashi, Y., Ueda, T., \& Kakuta, Y. (1998). Effective width for shear failure of RC deep slabs. Transactions of the Japan Concrete Institute, 20, pp.209216.

Gastebled, O. J., \& May, I. M. (2001). Fracture Mechanics Model Applied to Shear Failure of Reinforced Concrete Beams Without Stirrups. ACI Structural Journal, 98(2), 184-190. https://doi.org/10.14359/10186

Genikomsou, A. S., \& Polak, M. A. (2015). Finite element analysis of punching shear of concrete slabs using damaged plasticity model in ABAQUS. Engineering Structures, 98, 38-48. https://doi.org/10.1016/j.engstruct.2015.04.016

Ghannoum, W. M. (1998). Size Effect on Shear Strength of Reinforced Concrete Beams (p. 126). p. 126. https://doi.org/10.1177/1369433216658486

Gurutzeaga, M., Oller, E., Ribas, C., Cladera, A., \& Marí, A. (2015). Influence of the longitudinal reinforcement on the shear strength of one-way concrete slabs. Materials and Structures/Materiaux et Constructions, 48(8), 2597-2612. https://doi.org/10.1617/s11527-014-0340-5

Hedman, O., \& Losberg, A. (1978). Design of Concrete Structures with Regard to Shear Forces. In CEB Bulletin 126 (pp. 184-209d). Paris.

Heger, F. J., \& McGrath, T. J. (1980). Design method for reinforced concrete pipe and box sections. Massachusetts; San Francisco, California: Simpson Gumpertz \& Heger Inc.

Islam, M. S., Pam, H. J., \& Kwan, A. K. H. (1998). Shear capacity of high-strength 
concrete beams with their point of inflection within the shear span. Proceedings of the Institution of Civil Engineers: Structures and Buildings., 128, 91-99.

https://doi.org/10.1680/istbu.1998.30038

Jäger, T. (2007). Querkraftwiderstand und Verformungsvermögen von Stahlbetonplatten (Shear and Deformation Capacity of Reinforced Concrete Slabs). PhD thesis, ETH Zurich, Zurich, Switzerland.

Jäger, T., \& Marti, P. (2005). Versuche zum Querkraftwiderstand und zum Verformungsvermogen von Stahlbetonplatten (Experiments on the Shear and Deformation Capacity of Reinforced Concrete Slabs). Monograph, ETH Zurich, Zurich, Switzerland.

Jäger, Thomas. (2002). Shear strength and deformation capacity of reinforced concrete slabs. Proceedings of the 4th International PhD Symposium in Civil Engineering, 280-286. Munich, Germany.

Jørgensen, H. B., Hoang, L. C., Fabrin, L. S., \& Maagaard, J. (2013). Influence of high axial tension on the shear strength of non-shear RC beams. Proceedings of the International IABSE Conference: Assessment, Upgrading, Refurbishment of Infrastructures. https://doi.org/10.2749/222137813806474309

Kani, G. N. J. (1967). How Safe are Our Large Reinforced Concrete Beams? ACI Journal Proceedings, 64(3), 128-141. https://doi.org/10.14359/7549

Kani, M. W., Huggins, M. W. (Mark W., \& Wittkopp, R. R. (1979a). Kani on shear in reinforced concrete. Department of Civil Engineering, University of Toronto, Canada.

Kani, M. W., Huggins, M. W., \& Wittkopp, R. R. (1979b). Kani on shear in reinforced concrete. University of Toronto, Dept. of Civil Engineering.

Konig, G., \& Fischer, J. (1995). Model uncertainties concerning design equations for the shear capacity of concrete members without shear reinforcement. In CEB (Ed.), In CEB Bulletin 224, Model Uncertainties and Concrete Barrier for Environmental Protection (pp. 49-100). Lausanne, Switzerland.

Krips, M. (1985). Rißbreitenbeschränkung im Stahlbeton und Spannbeton (Crack width restriction in reinforced concrete and prestressed concrete). Berlin: Ernst \& Sohn.

Kuchma, D. A., Wei, S., Sanders, D. H., Belarbi, A., \& Novak, L. C. (2019).

Development of One-Way Shear Design Provisions of ACI 318-19 for Reinforced Concrete. ACI Structural Journal, 116(4), 285-295. https://doi.org/10.14359/51716739

Kupfer, H. B., \& Gerstle, K. H. (1973). Behavior of Concrete under Biaxial Stresses. Journal of the Engineering Mechanics Division, 99(4), 853-866.

Lantsoght, E. O. L., van der Veen, C., Walraven, J. C., \& de Boer, A. (2015). Database of wide concrete members failing in shear. Magazine of Concrete Research, 67(1), 33-52. https://doi.org/10.1680/macr.14.00137

Lantsoght, E.O.L. (2013). Shear in Reinforced Concrete Slabs under Concentrated Loads Close to Supports. Ph.D. Thesis, Faculty of Civil Engineering and Geosciences, Delft University of Technology. 
Lantsoght, E.O.L., Van Der Veen, C., \& Walraven, J. C. (2013). Shear in One-Way Slabs under Concentrated Load Close to Support. ACI Structural Journal, 110(2).

Lantsoght, E.O.L., van der Veen, C., Walraven, J. C., \& de Boer, A. (2015). Transition from one-way to two-way shear in slabs under concentrated loads. Magazine of Concrete Research, 67(17), 909-922. https://doi.org/10.1680/macr.14.00124

Lantsoght, Eva Olivia Leontien. (2012). Shear capacity of reinforced concrete slab bridges under a wheel load close to the support - Literature review. In Report $n r$. 25.5-12-11.

Lantsoght, Eva Olivia Leontien, Veen, C. van der, \& Walraven, J. C. (2013). Shear in one-way slabs under concentrated load close to support. ACI Structural Journal, 110(2), 275-284. https://doi.org/10.14359/51684407

Leonhardt, F., \& Walther, R. (1962). Schubversuche an einfeldrigen Stahlbetonbalken mit und ohne Schubbewehrung zur Ermittlung der Schubtragfähigkeit und der oberen Schubspannungsgrenze. Berlin: Beuth.

Lubell, Adam S., Sherwood, E. G., Bentz, E. C., \& Collins, M. P. (2004). Safe Shear Design of Large, Wide Beam. Concrete International.

Lubell, Adam Scott. (2006). Shear in Wide Reinforced Concrete Members. PhD dissertation. University of Toronto, Canadá.

MacGregor, J. G., \& Hanson, J. M. (1969). Proposed Changes in Shear Provisions for Reinforced and Prestressed Concrete Beams*. ACI Journal Proceedings, 66(4), 276-288. https://doi.org/10.14359/7360

Marí, A., Bairán, J., Cladera, A., Oller, E., \& Ribas, C. (2015). Shear-flexural strength mechanical model for the design and assessment of reinforced concrete beams. Structure and Infrastructure Engineering, 11(11), 1399-1419. https://doi.org/10.1080/15732479.2014.964735

Marí, A., Bairán, J. M., Cladera, A., \& Oller, E. (2016). Shear Design and Assessment of Reinforced and Prestressed Concrete Beams Based on a Mechanical Model. Journal of Structural Engineering, 142(10), 17p. https://doi.org/10.1061/(ASCE)ST.1943-541X.0001539

Marí, A., Cladera, A., Bairán, J., Oller, E., \& Ribas, C. (2014). Shear-flexural strength mechanical model for the design and assessment of reinforced concrete beams subjected to point or distributed loads. Frontiers of Structural and Civil Engineering, 8(4), 337-353. https://doi.org/10.1007/s11709-014-0081-0

Muttoni, A., \& Fernandez Ruiz, M. (2010). Shear in slabs and beams: should they be treated in the same way? Fédération Internationale Du Béton (Fib) Bulletin, $N^{\circ} 57$, $105-128$.

Muttoni, A., \& Ruiz, M. F. (2008). Shear Strength of Members without Transverse Reinforcement as Function of Critical Shear Crack Width. ACI Structural Journal, 105(2), 163-172. https://doi.org/10.14359/19731

Olonisakin, A. A., \& Alexander, S. D. B. (1999). Mechanism of shear transfer in a reinforced concrete beam. Canadian Journal of Civil Engineering, 26(6), 810-817. 
Rajagopalan, K. S., \& Ferguson, P. M. (1968). Exploratory Shear Tests Emphasizing Percentage of Longitudinal Steel. ACI Journal Proceedings, 65(8), 634-638. https://doi.org/10.14359/7501

Regan, P. E. (1987). Shear Resistance of Members without Shear Reinforcement; Proposal for CEB Model Code MC90 (pp. 1-28). pp. 1-28. Polytechnic of Central London, London, UK.

Reineck, K.-H. (1991a). Model for Structural Concrete Members without Transverse Reinforcement. IABSE Colloquium Structural Concrete, IABSE Report, IABSE, 643-648. Zurich.

Reineck, K.-H. (1991b). Ultimate shear force of structural concrete members Without Transverse Reinforcement Derived From a Mechanical Model (SP-885). ACI Structural Journal, 88(5), 592-602. https://doi.org/10.14359/2784

Reissen, K. (2016). Zum Querkrafttragverhalten von einachsig gespannten Stahlbetonplatten ohne Querkraftbewehrung unter Einzellasten. PhD Thesis (Doctor of Engineering), Faculty of Civil Engineering, RWTH Aachen University, Aachen, Germany.

Reissen, K., Classen, M., \& Hegger, J. (2018). Shear in reinforced concrete slabsExperimental investigations in the effective shear width of one-way slabs under concentrated loads and with different degrees of rotational restraint. Structural Concrete, 19(1), 36-48. https://doi.org/10.1002/suco.201700067

Reissen, Karin, \& Hegger, J. (2013). Experimentelle Untersuchungen zum Querkrafttragverhalten von auskragenden Fahrbahnplatten unter Radlasten. BetonUnd Stahlbetonbau, 108(5), 315-324. https://doi.org/10.1002/best.201200072

Sagaseta, J., \& Vollum, R. L. (2010). Shear design of short-span beams. Magazine of Concrete Research, 62(4), 267-282. https://doi.org/10.1680/macr.2010.62.4.267

Serna-Ros, P., Fernandez-Prada, M. A., Miguel-Sosa, P., \& Debb, O. A. R. (2002). Influence of stirrup distribution and support width on the shear strength of reinforced concrete wide beams. Magazine of Concrete Research, 54(3), 181-191. https://doi.org/10.1680/macr.2002.54.3.181

SIA. (2013). Code 262 for concrete structures. Zürich: Swiss Society of Engineers and Architects.

Sigrist, V., Bentz, E., Ruiz, M. F., Foster, S., \& Muttoni, A. (2013). Background to the fib Model Code 2010 shear provisions - part I: beams and slabs. Structural Concrete, 14(3), 195-203. https://doi.org/10.1002/suco.201200066

Sousa, A. M. ., Lantsoght, E. O. L., \& El Debs, M. K. (2019). Database of wide RC members without Stirrups Failing in Shear. https://doi.org/10.5281/zenodo.3530823

Taylor, H. P. J. (1974). The fundamental behavior of reinforced concrete beams in bending and shear. Special Publication, 42, 43-78. https://doi.org/10.14359/17279

Tung, N. D., \& Tue, N. V. (2016a). A new approach to shear design of slender reinforced concrete members without transverse reinforcement. Engineering Structures, 107, 180-194. https://doi.org/10.1016/J.ENGSTRUCT.2015.04.015 
Tung, N. D., \& Tue, N. V. (2016b). Effect of support condition and load arrangement on the shear response of reinforced concrete beams without transverse reinforcement. Engineering Structures, 111, 370-382 [in German]. https://doi.org/10.1016/J.ENGSTRUCT.2015.12.022

Vecchio, F. J., \& Collins, M. P. (1986). The Modified Compression-Field Theory for Reinforced Concrete Elements Subjected to Shear. ACI Journal Proceedings, 83(2), 219-231. https://doi.org/10.14359/10416

Vollum, R. L., \& Fang, L. (2015). Shear enhancement near supports in RC beams. Magazine of Concrete Research, 67(9), 443-458. https://doi.org/10.1680/macr.14.00309

Walraven, J. C. (1980). Aggregate Interlock: a Theoretical and Experimental Analysis. PhD. Thesis, Delft University of Technology.

Walraven, J. C. (1981). Fundamental Analysis of Aggregate Interlock. Journal of the Structural Division, ASCE, 107(11), 2245-2270.

Walraven, J., \& Lehwalter, N. (1994). Size Effects in Short Beams Loaded in Shear. ACI Structural Journal, 91(5), 585-593. https://doi.org/10.14359/4177

Yang, Y., den Uijl, J., \& Walraven, J. (2016). Critical shear displacement theory: on the way to extending the scope of shear design and assessment for members without shear reinforcement. Structural Concrete, 17(5), 790-798. https://doi.org/10.1002/suco.201500135

Yang, Y., Walraven, J., \& Uijl, J. den. (2017). Shear Behavior of Reinforced Concrete Beams without Transverse Reinforcement Based on Critical Shear Displacement. Journal of Structural Engineering, 143(1), 04016146. https://doi.org/10.1061/(ASCE)ST.1943-541X.0001608

Yu, Q., Le, J.-L., Hubler, M. H., Wendner, R., Cusatis, G., \& Bažant, Z. P. (2015). Comparison of main models for size effect on shear strength of reinforced and prestressed concrete beams. Structural Engineering Report No. 15-03/936x, Prepared for ACI Committee 445, Shear and Torsion, Vol. 17, pp. 778-789. https://doi.org/10.1002/suco.201500126

Yu, Q., Le, J. L., Hubler, M. H., Wendner, R., Cusatis, G., \& Bažant, Z. P. (2016). Comparison of main models for size effect on shear strength of reinforced and prestressed concrete beams. Structural Concrete, 17(5), 778-789. https://doi.org/10.1002/suco.201500126

Zsutty, B. (1968). Beam Shear Strength Prediction by. ACI Journal Proceedings, 5(6571), 943-951. 


\section{Figure captions}

Figure 1 - Main types of loads on wide members: a) concentrated in the shear span and distributed along the width; b) concentrated in the span and width directions (not included in the scope of this study) and c) distributed load in both span and width direction.

Figure 2 - Differences in the cracking pattern of members with different $b / d$ ratios identified by Conforti et al. (2017)

Figure 3 - a) Arching action produced by a combination of the elbow-shaped strut and direct compression strut in the simply supported beam and b) direct compression strut in a cantilever member.

Figure 4 -Bending moments in structures with a) fully clamped support and b) partially clamped support.

Figure $5-$ a) continuous specimen under distributed load; b) equivalent simply supported member when $M_{\text {sup }}<M_{\text {span }}$ and c) equivalent problem when $M_{\text {sup }}>M_{\text {span }}$, based on the CWSB model from Tung and Tue (2016b).

Figure 6 - Geometric parameters of the shear span under a) concentrated loads and b) uniformly distributed loads. 50

Figure 7 - Cases of load arrangement changes that can result in improved shear capacities for cantilever members: (i) under distributed loads instead of concentrated loads; (ii) distributed loads on longer shear spans and (iii) members pre-loaded by line loads

Figure 8 - Distribution of parameters in database: (a) concrete compressive strength $f_{c}$; (b) reinforcement ratio $\rho$; (c) effective depth $d_{l}$; (d) clear shear span to effective depth ratio $a_{v} / d$; e) rebar spacing to effective depth ratio $s / d$; f) member width to effective depth ratio $b / d$.

Figure 9 - Normalized shear strength by section geometry and: (a) square root of the concrete compressive strength; (b) cube root of the concrete compressive strength.

Figure 10. Studies on parameters based on normalized shear strength for all entries in the database, influence of (a) longitudinal reinforcement ratio $\rho_{\ell}$; (b) effective depth $d$; (c) clear shear span to depth ratio $a_{v} / d$; (d) shear slenderness $M / V d$; (e) rebar spacing to effective depth ratio $s / d ;$ f) member width to effective depth ratio $b / d$ 54 
Figure 11 - Relation between experimental shear capacities and different definitions of shear slenderness $\lambda:$ a) shear slenderness based on the ratio $\max \left\{a_{1} ; a_{2}\right\} / d$ regardless of the bending moments $M_{\text {sup }}$ and $M_{\text {span }}$; b) definition of $\max \left\{a_{1} ; a_{2}\right\} / d$ modified for continuous members under uniformly distributed loads according to $M_{\text {sup }}$

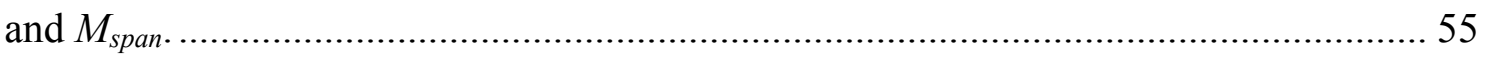

Figure 12 - Effect of the degree of rotational restraint $d_{r}$ on the normalized shear strength of wide members according to the load arrangement. (CL) members subjected to concentrated loads and (DL) members subjected to uniformly distributed loads 56 


\section{Table captions}

Table 1 - Proposed shear slenderness definition according to the static system and internal forces distribution.....

Table 2 - Semi-empirical models of shear strength.................................... 58

Table 3 - Mechanical models of shear strength - Part I. ............................. 59

Table 4 - Mechanical models of shear strength - Part II................................ 61

Table 5 - Mechanical models of shear strength - Part III.............................. 62

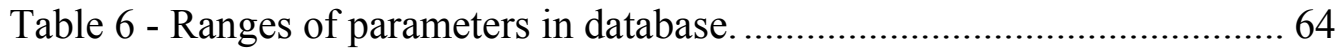

Table 7 - Shear behavior of wide RC members according to the parameters studies showed in Figure 10.

Table 8 - Behavior of RC members according to the degree of rotational restraint at the support and the load arrangement: (CL) members subjected to concentrated loads and (DL) members subjected to uniformly distributed loads. 67

Table 9 - Statistical evaluation of the $V_{\text {exp }} / V_{c a l}$ ratio with semi-empirical models according to the structural system. 68

Table 10 - Statistical evaluation of the $V_{\text {exp }} / V_{\text {cal }}$ ratio with mechanical models according to the structural system.

Table 11 - Statistical evaluation of the $V_{\text {exp }} / V_{c a l}$ ratio with mechanical models according to the $b / d$ ratio. 70

Table 12 - Statistical evaluation of the $V_{\text {exp }} / V_{c a l}$ ratio with mechanical models according to the shear slenderness $\lambda$. 71 


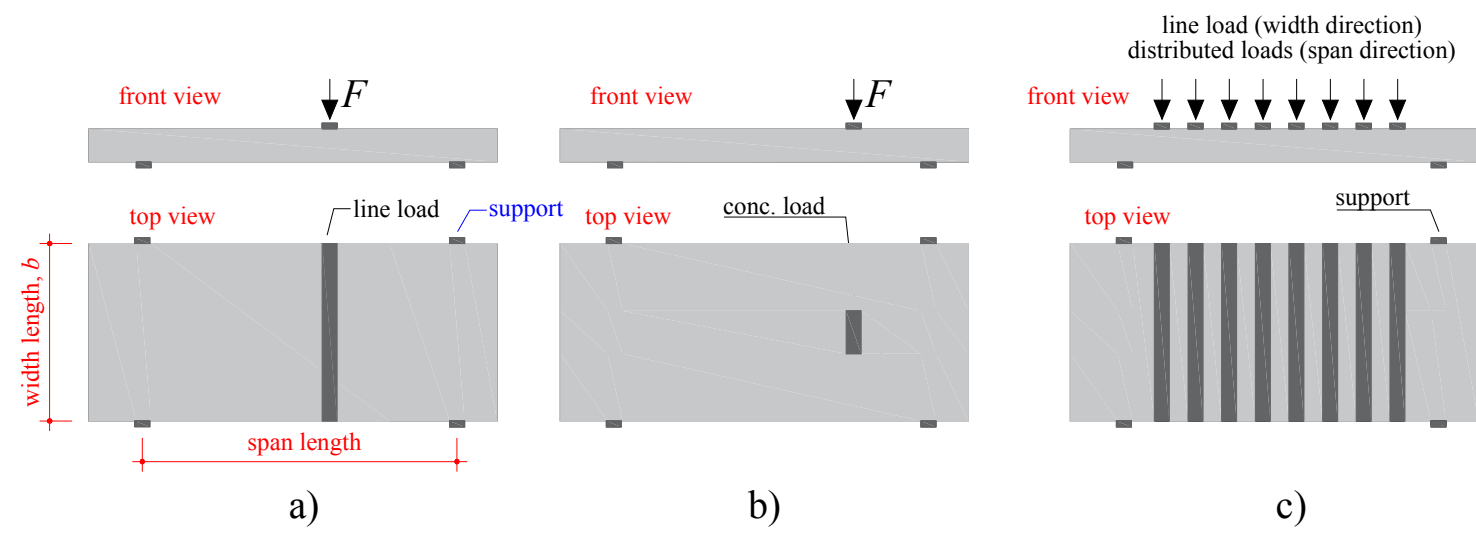

Figure 1 - Main types of loads on wide members: a) concentrated in the shear span and distributed along the width; b) concentrated in the span and width directions (not included in the scope of this study) and c) distributed load in both span and width direction. 
CASE 1

symmetry plane

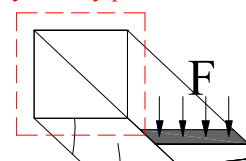

CASE 2

symmetry plane

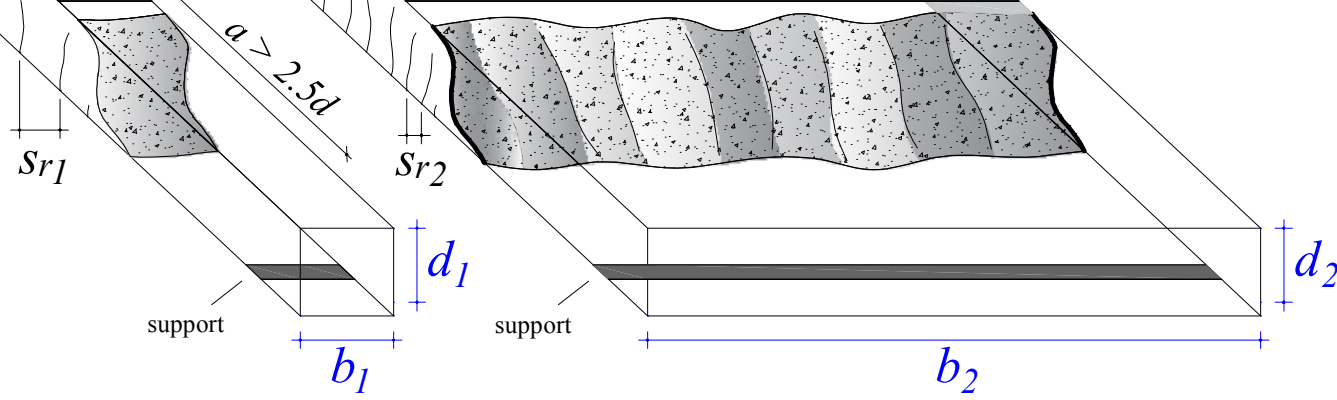

Figure 2 - Differences in the cracking pattern of members with different $b / d$ ratios identified by Conforti et al. (2017). 


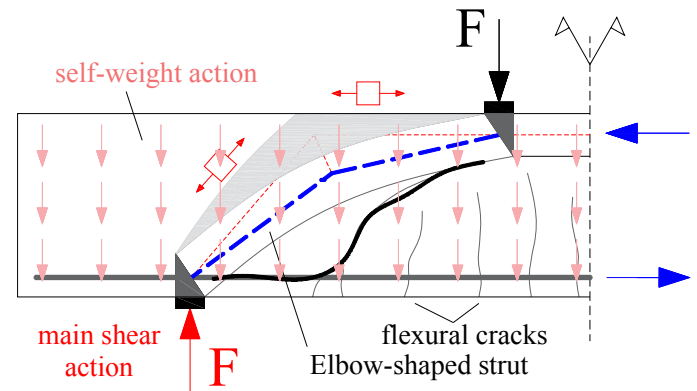

a)

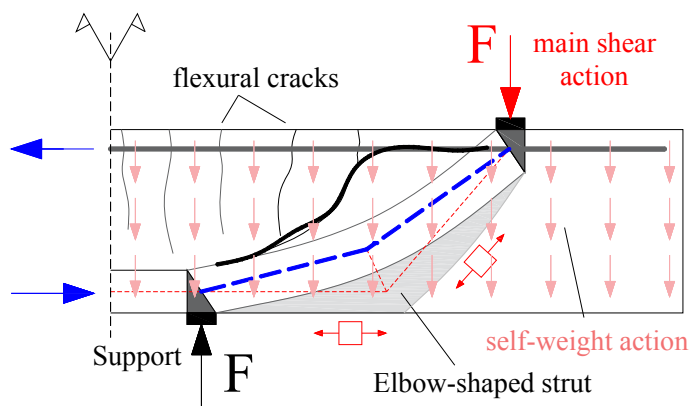

b)

Figure $3-$ a) Arching action produced by a combination of the elbow-shaped strut and direct compression strut in the simply supported beam and b) direct compression strut in a cantilever member. 


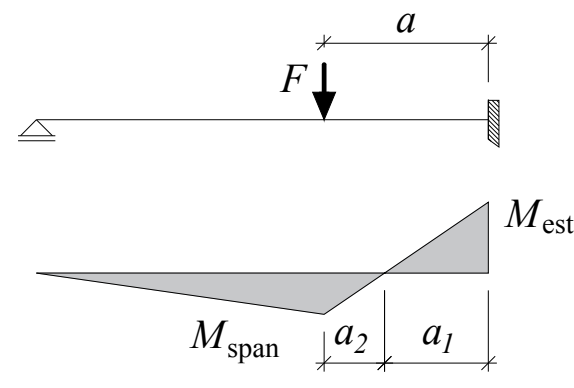

a)

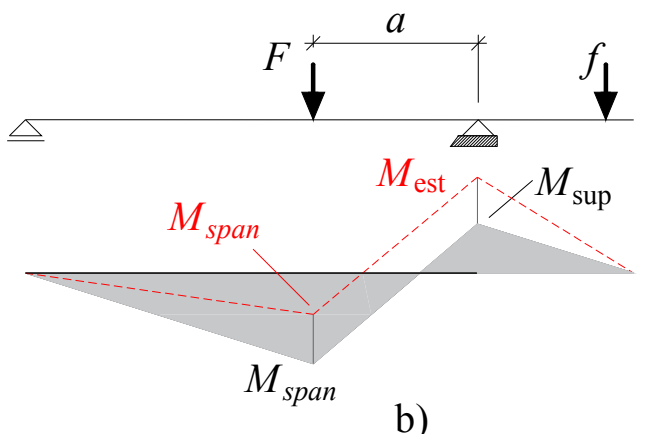

b)

Figure 4 -Bending moments in structures with a) fully clamped support and b) partially clamped support. 


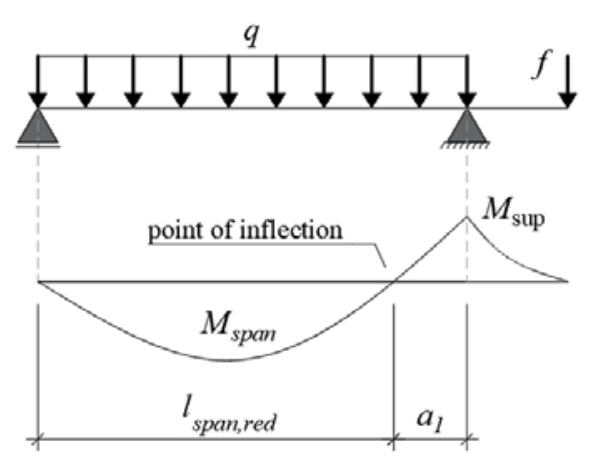

a)

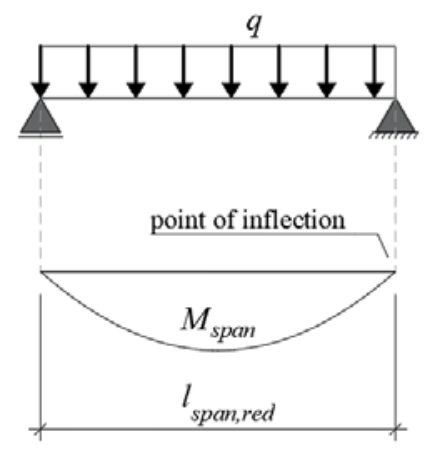

b) $M_{\text {sup }}<M_{\text {span }}$

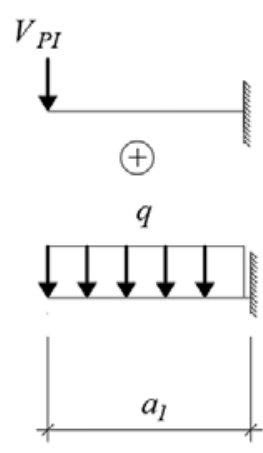

c) $M_{\text {sup }}>M_{\text {span }}$

Figure 5 - a) continuous specimen under distributed load; b) equivalent simply supported member when $M_{\text {sup }}<M_{\text {span }}$ and c) equivalent problem when $M_{\text {sup }}>M_{\text {span }}$, based on the CWSB model from Tung and Tue (2016b). 


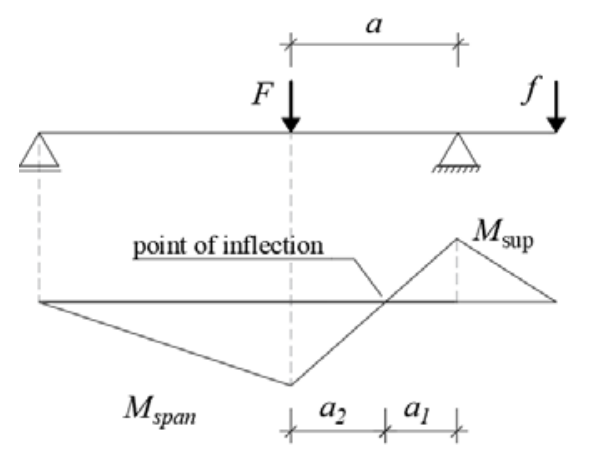

a)

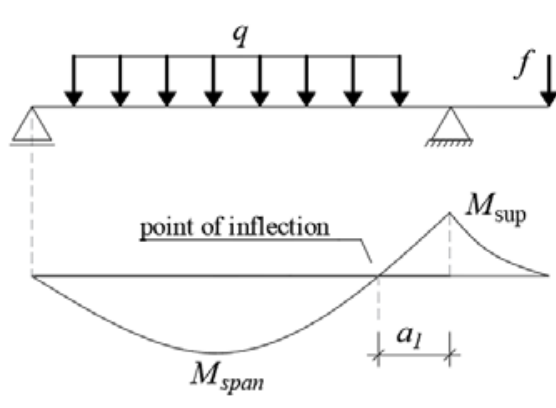

b)

Figure 6 - Geometric parameters of the shear span under a) concentrated loads and b) uniformly distributed loads. 


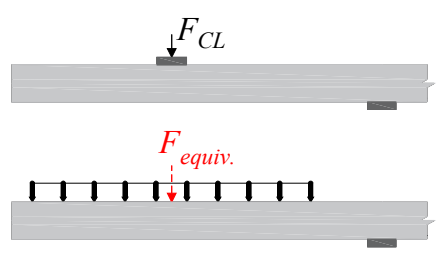

a)

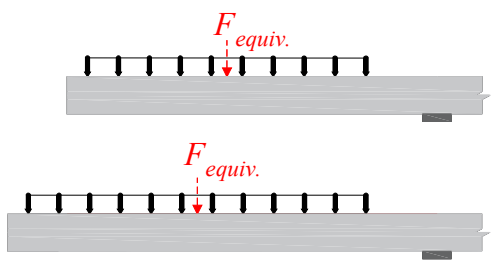

b)

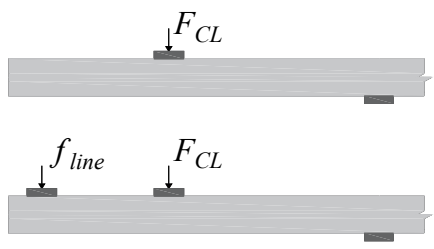

c)

Figure 7 - Cases of load arrangement changes that can result in improved shear capacities for cantilever members: a) under distributed loads instead of concentrated loads; b) distributed loads on longer shear spans; and c) members pre-loaded by line loads. 


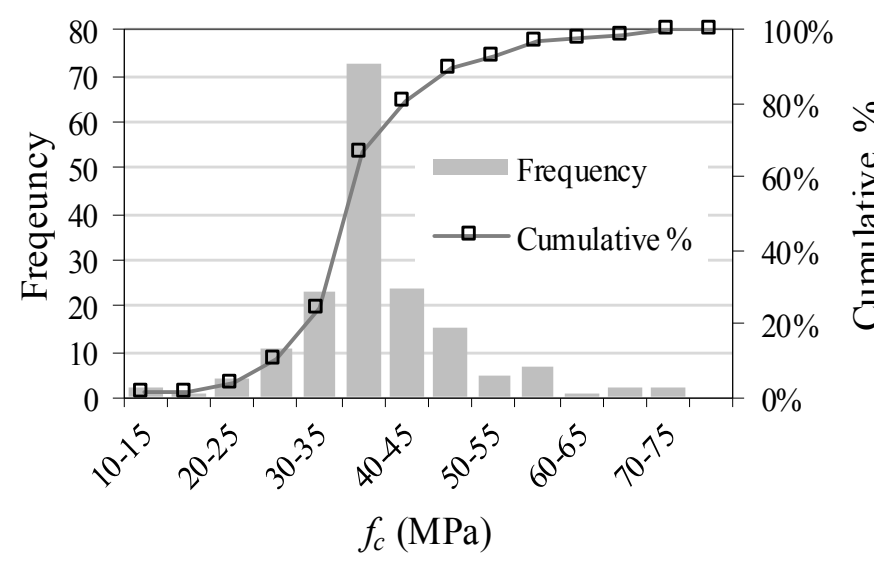

a)

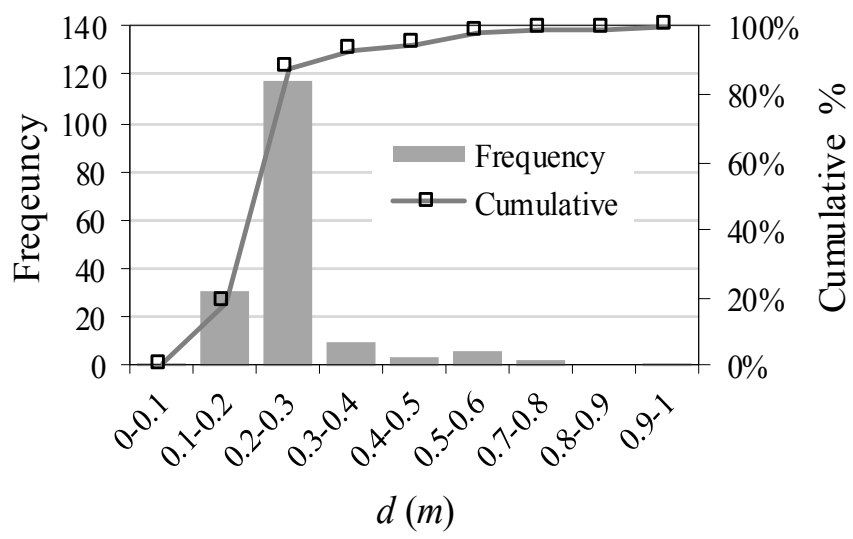

c)

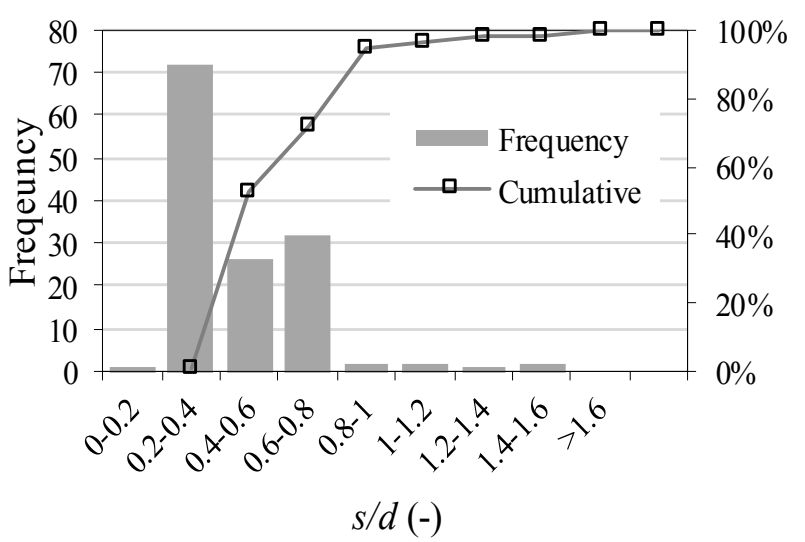

e)
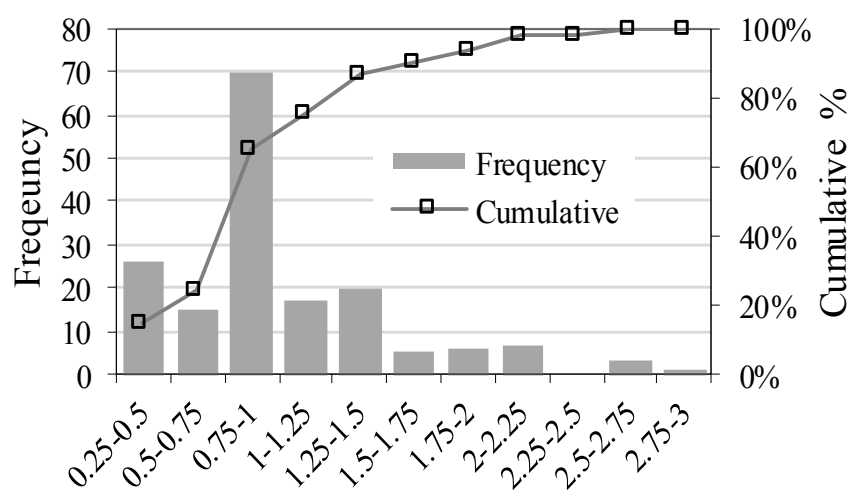

$\rho_{l}(\%)$

b)

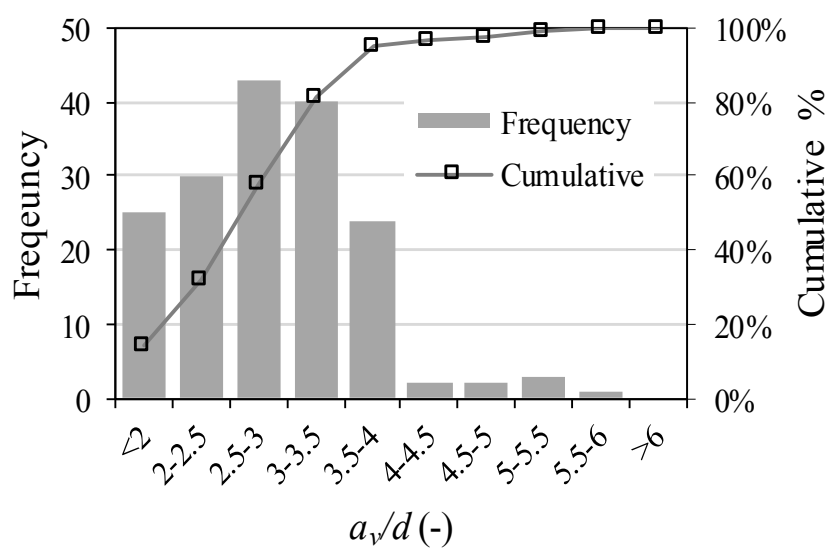

d)

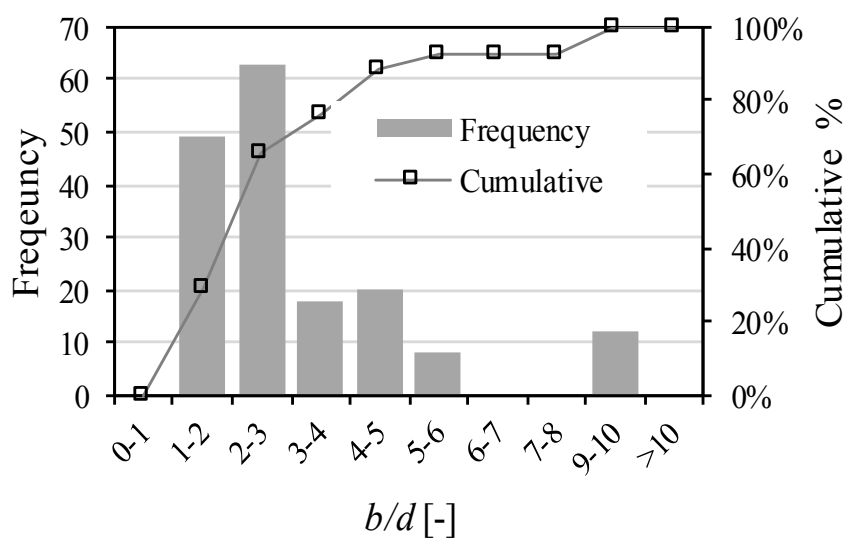

f)

Figure 8 - Distribution of parameters in database: (a) concrete compressive strength $f_{c}$; (b) reinforcement ratio $\rho$; (c) effective depth of the longitudinal reinforcement $d$; (d) clear shear span to effective depth ratio $a_{v} / d$; e) rebar spacing to effective depth ratio $s / d ;$ f) member width to effective depth ratio $b / d$. 


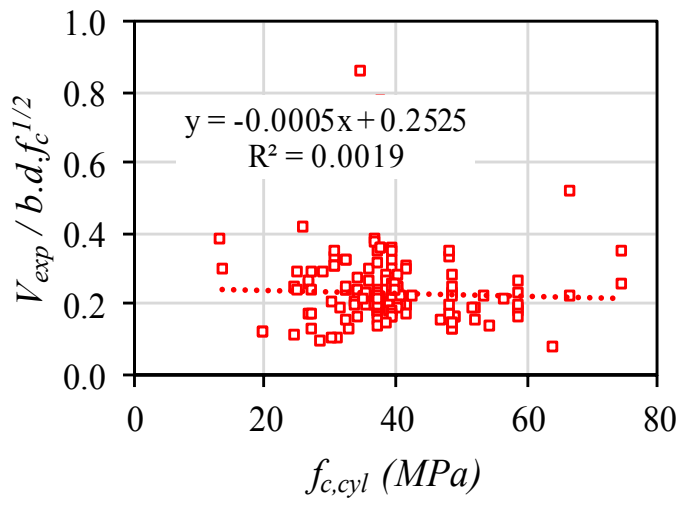

a)

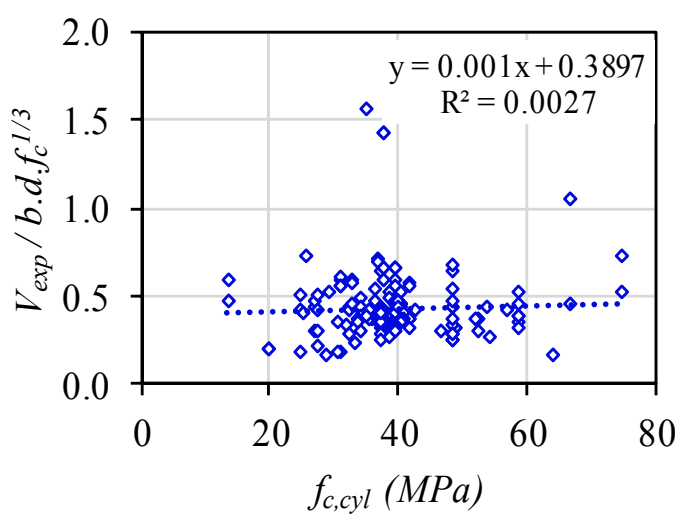

b)

Figure 9 - Normalized shear strength by section geometry and: (a) square root of the concrete compressive strength; (b) cube root of the concrete compressive strength. 


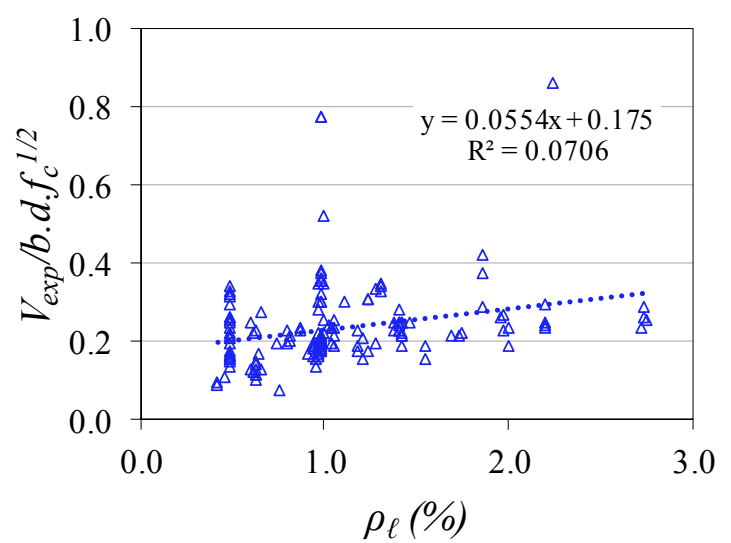

a)

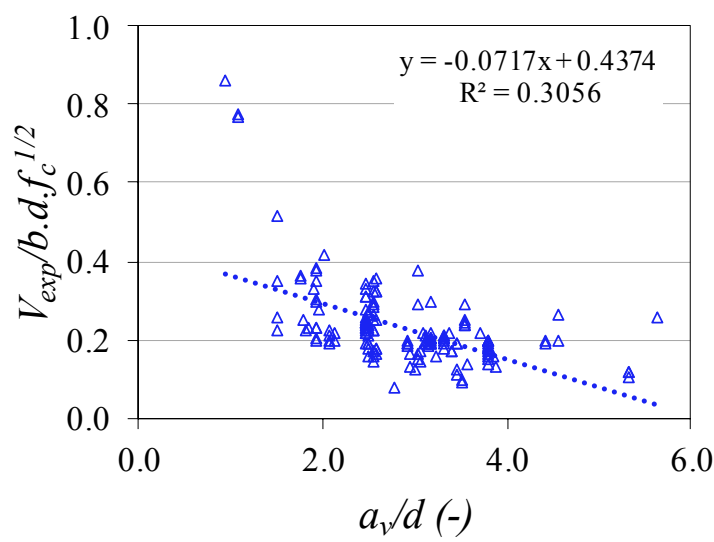

c)

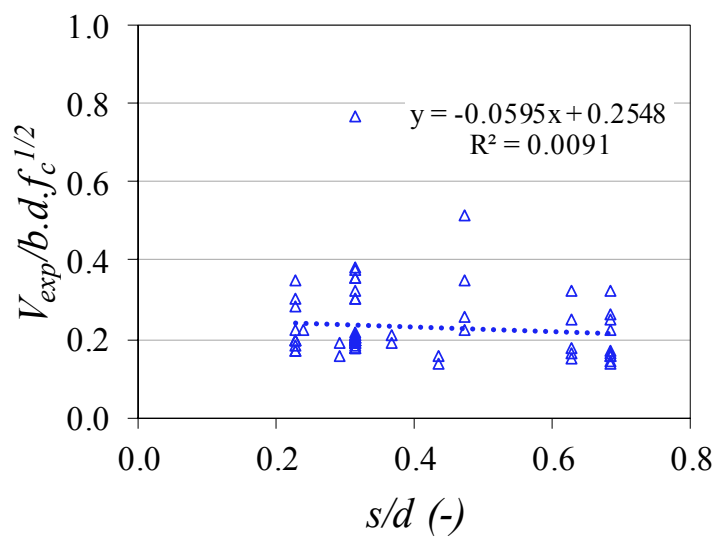

e)

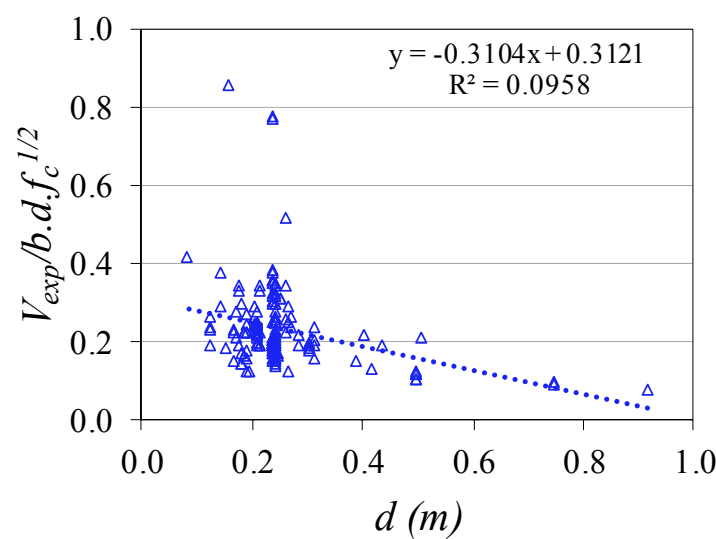

b)

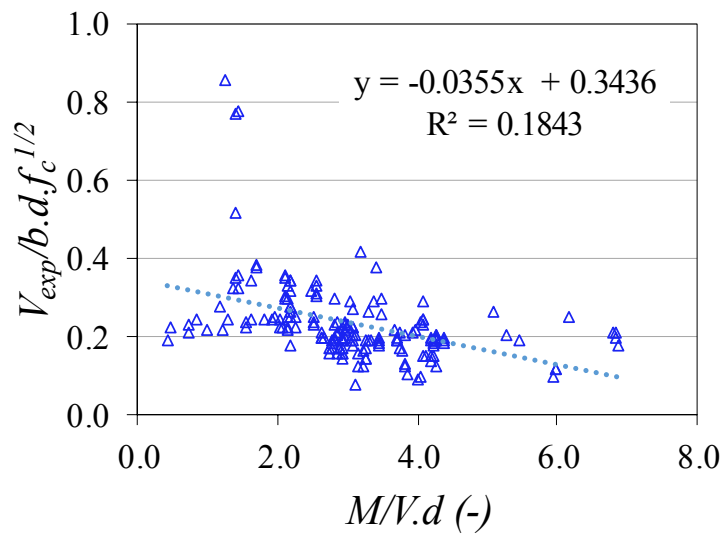

d)

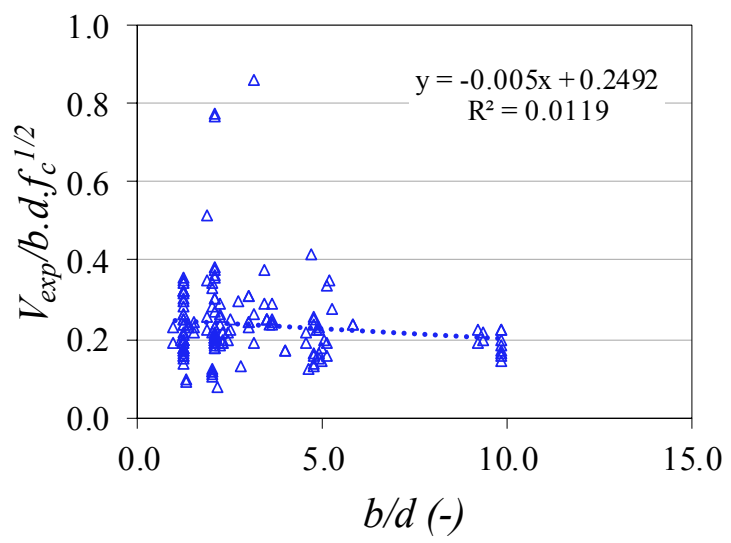

f)

Figure 10. Studies on parameters based on normalized shear strength for the database, with the influence of (a) longitudinal reinforcement ratio $\rho_{\ell}$; (b) effective depth $d$; (c) clear shear span to depth ratio $a_{v} / d$; (d) shear slenderness $M / V d$; (e) rebar spacing to effective depth ratio $s / d ;$ f) member width to effective depth ratio $b / d$. 


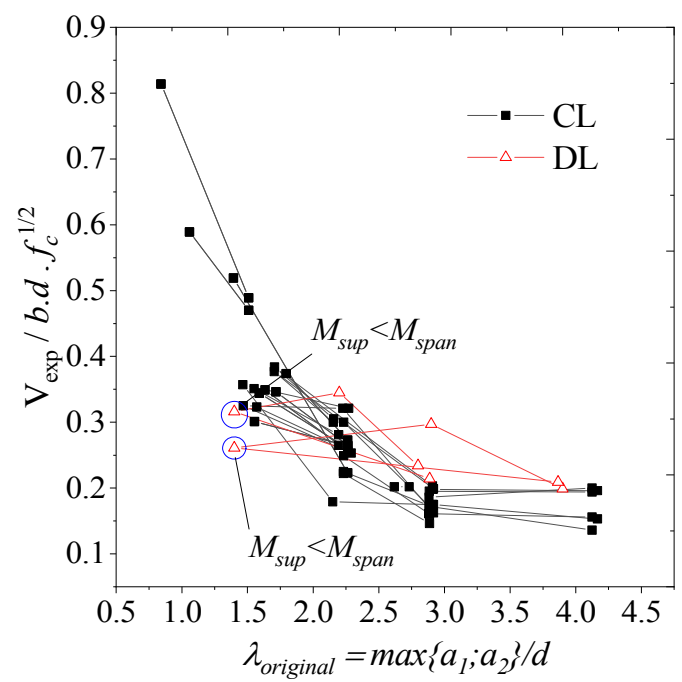

a)

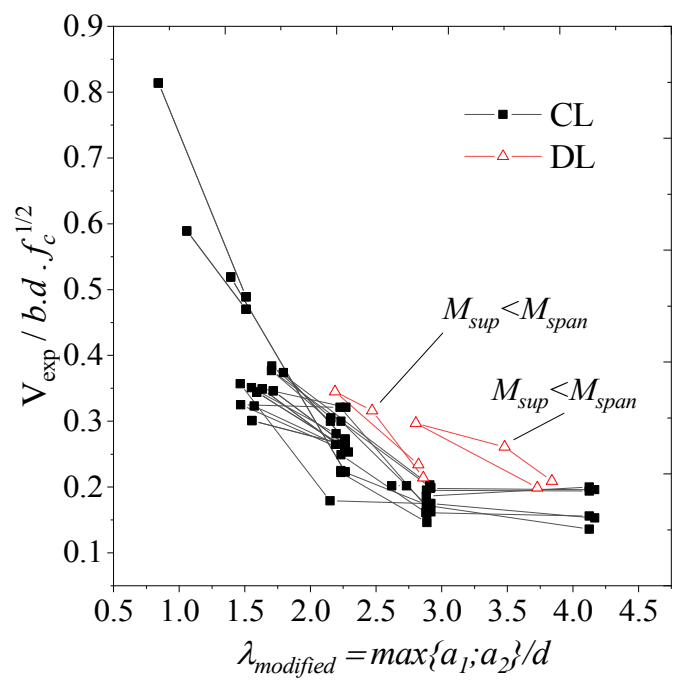

b)

Figure 11 - Relation between experimental shear capacities and different definitions of shear slenderness $\lambda:$ a) shear slenderness based on the ratio $\max \left\{a_{1} ; a_{2}\right\} / d$ regardless of the bending moments $M_{\text {sup }}$ and $M_{\text {span }} ;$ b) definition of $\max \left\{a_{1} ; a_{2}\right\} / d$ modified for continuous members under uniformly distributed loads according to $M_{\text {sup }}$ and $M_{\text {span }}$. 


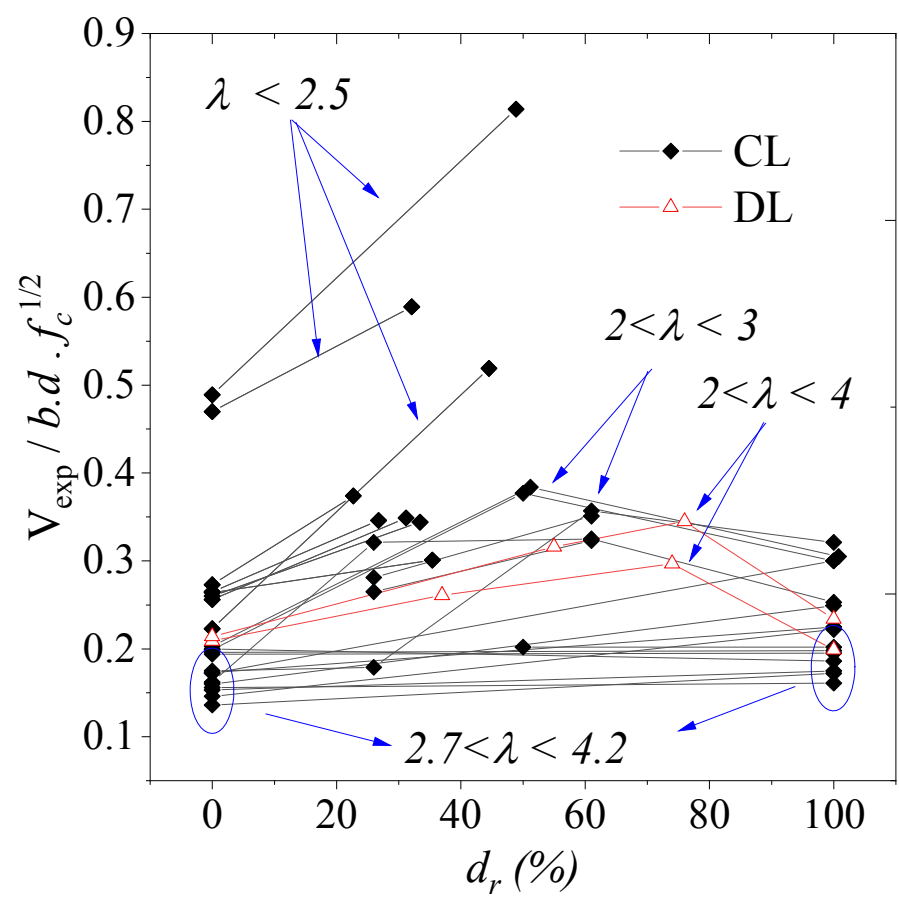

Figure 12 - Effect of the degree of rotational restraint $d_{r}$ on the normalized shear strength of wide members according to the load arrangement. (CL) members subjected to concentrated loads and (DL) members subjected to uniformly distributed loads. 
Table 1 - Proposed shear slenderness definition according to the static system and internal forces distribution

\begin{tabular}{cccc}
\hline Structural system & Load arrangement & $\begin{array}{c}\text { Bending } \\
\text { moments }\end{array}$ & Shear slenderness $\lambda$ \\
\hline \multirow{2}{*}{ Simply supported } & Concentrated load & - & $\max \left\{a_{1} ; a_{2}\right\} / d$ \\
\cline { 2 - 4 } & Unif. Distributed load & - & $M_{\max } / V_{\max } \cdot d=l_{\text {span }} / 4 d$ \\
\hline \multirow{2}{*}{ Cantilever } & Concentrated load & - & $\max \left\{a_{1} ; a_{2}\right\} / d$ \\
\cline { 2 - 4 } & Unif. Distributed load & - & $\max \left\{a_{1} ; a_{2}\right\} / d$ \\
\hline \multirow{2}{*}{$\begin{array}{c}\text { Continuous } \\
\text { member }\end{array}$} & Concentrated load & - & $\max _{\{\text {span, red }} / 4 d$ \\
\cline { 2 - 4 } & Unif. Distributed load & $\left.M_{\text {sup }}<a_{2}\right\} / d$ \\
\cline { 2 - 4 } & Unif. Distributed load & $M_{\text {sup }}>M_{\text {span }}$ & $\max \left\{a_{1} ; a_{2}\right\} / d$ \\
\hline
\end{tabular}


Table 2 - Semi-empirical models of shear strength.

\section{Code Reference Expression}

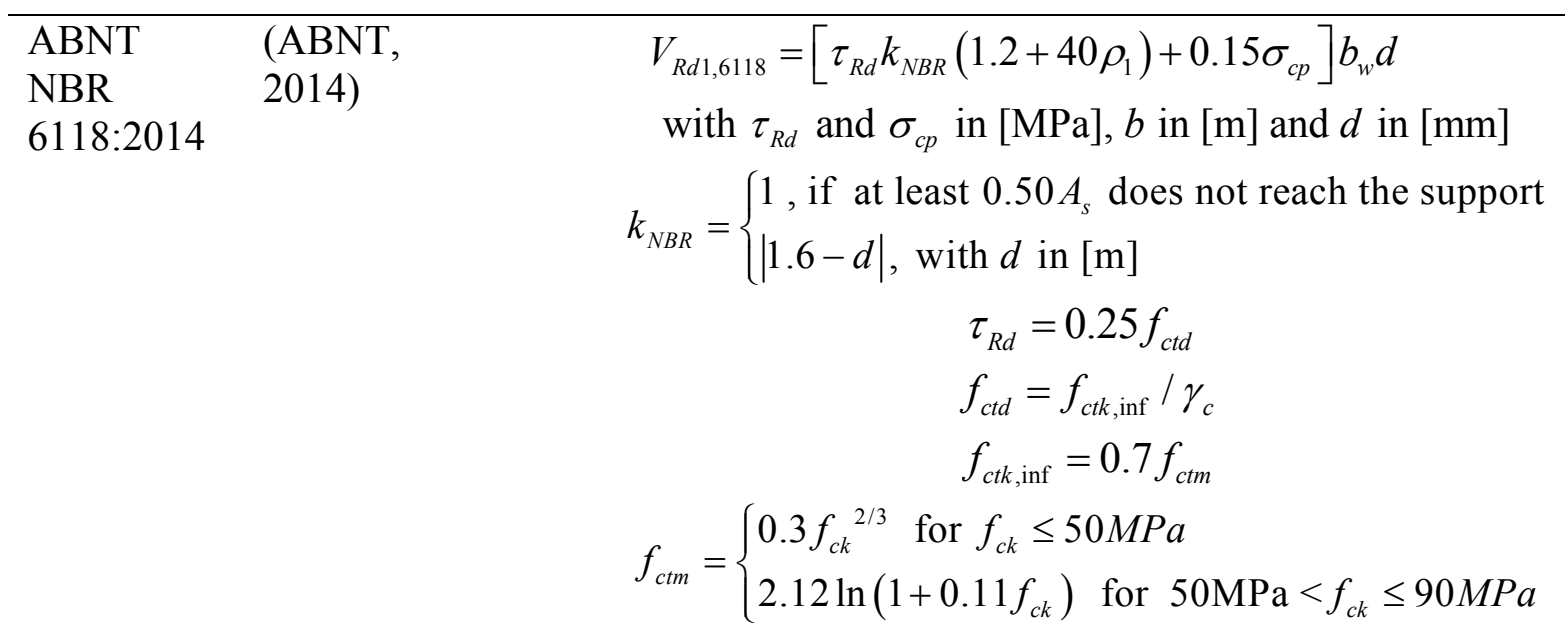

NEN 1992- (CEN,

1-1:2005 2005)

$V_{R d, c, E C 2}=\operatorname{Max}\left\{\begin{array}{l}{\left[C_{R d, c} k\left(100 \rho_{l} f_{c k}\right)^{1 / 3}+k_{1} \sigma_{c p}\right] b_{w} d=V_{R d, c 1}} \\ \left(v_{\min }+k_{1} \sigma_{c p}\right) b_{w} d=V_{R d, c 2}\end{array}\right.$

with $d$ in [mm] and $f_{c k}$ in [MPa]

$$
\begin{gathered}
v_{\min }=0.035 k^{3 / 2} f_{c k}{ }^{1 / 2} \\
C_{r d c}=0.18 \text { for NEN 1992-1-1:2005 } \\
k=1+\sqrt{\frac{200}{d} \leq 2, \text { with } d \text { in }[\mathrm{mm}] \text { and } f_{c k} \text { in }[\mathrm{MPa}]}
\end{gathered}
$$

$$
\beta= \begin{cases}1, & \text { if } a_{v} \geq 2 d_{\ell} \\ a_{v} / 2 d_{\ell}, & \text { if } 0.5 d_{\ell} \leq a_{v} \leq 2 d_{\ell} \\ 0.25, & \text { if } a_{v} \leq 0.5 d_{\ell}\end{cases}
$$

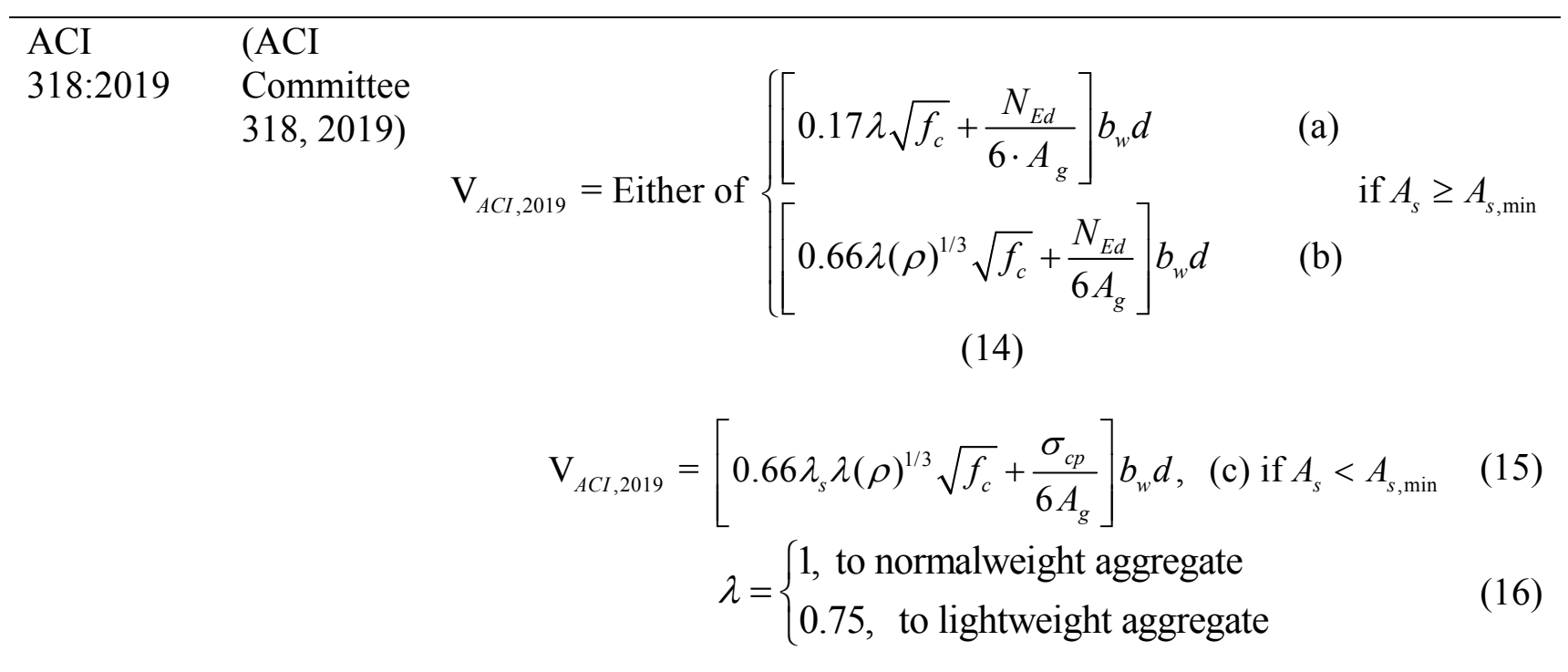




$$
\begin{array}{r}
\lambda_{s}=\sqrt{\frac{2}{1+0.004 d} \leq 1, \text { with } d \text { in }[\mathrm{mm}] \text { and } f_{c} \text { in }[\mathrm{MPa}]} \\
\text { limits : }\left\{\begin{array}{l}
\sqrt{f_{c}} \leq 8.3 \mathrm{MPa} \\
V_{A C I} \leq 0.42 \lambda \sqrt{f_{c}} b_{w} d \\
\frac{N_{E d}}{A_{g}} \leq 3.45 \mathrm{MPa}
\end{array}\right.
\end{array}
$$

\begin{tabular}{rlrl}
\hline ACI & (ACI & $V_{A C I, 2014, \text { simplified }}=0.17 \sqrt{f_{c k}} b_{w} d_{l}$ \\
318:2014 & Committee & \\
$318,2014)$ & $V_{A C I, 2014, \text { detailed }}$ & $=\left(0.16 \sqrt{f_{c k}}+17 \rho_{l} \frac{V d_{l}}{M}\right) b_{w} d_{l} \leq 0.29 \sqrt{f_{c k}} b_{w} d_{l}$ \\
with $f_{c k}$ in $[\mathrm{MPa}], b$ in $[m]$ and $d$ in $[\mathrm{mm}]$ \\
limits: $\left\{\begin{array}{l}\left\{V_{A C l, 2014} \leq 0.29 \sqrt{f_{c k}} b_{w} d\right. \\
\frac{V d_{l}}{M} \leq 1\end{array}\right.$
\end{tabular}

Continuation of Table 2

Table 3 - Mechanical models of shear strength - Part I.

Code Reference $\quad$ Expression




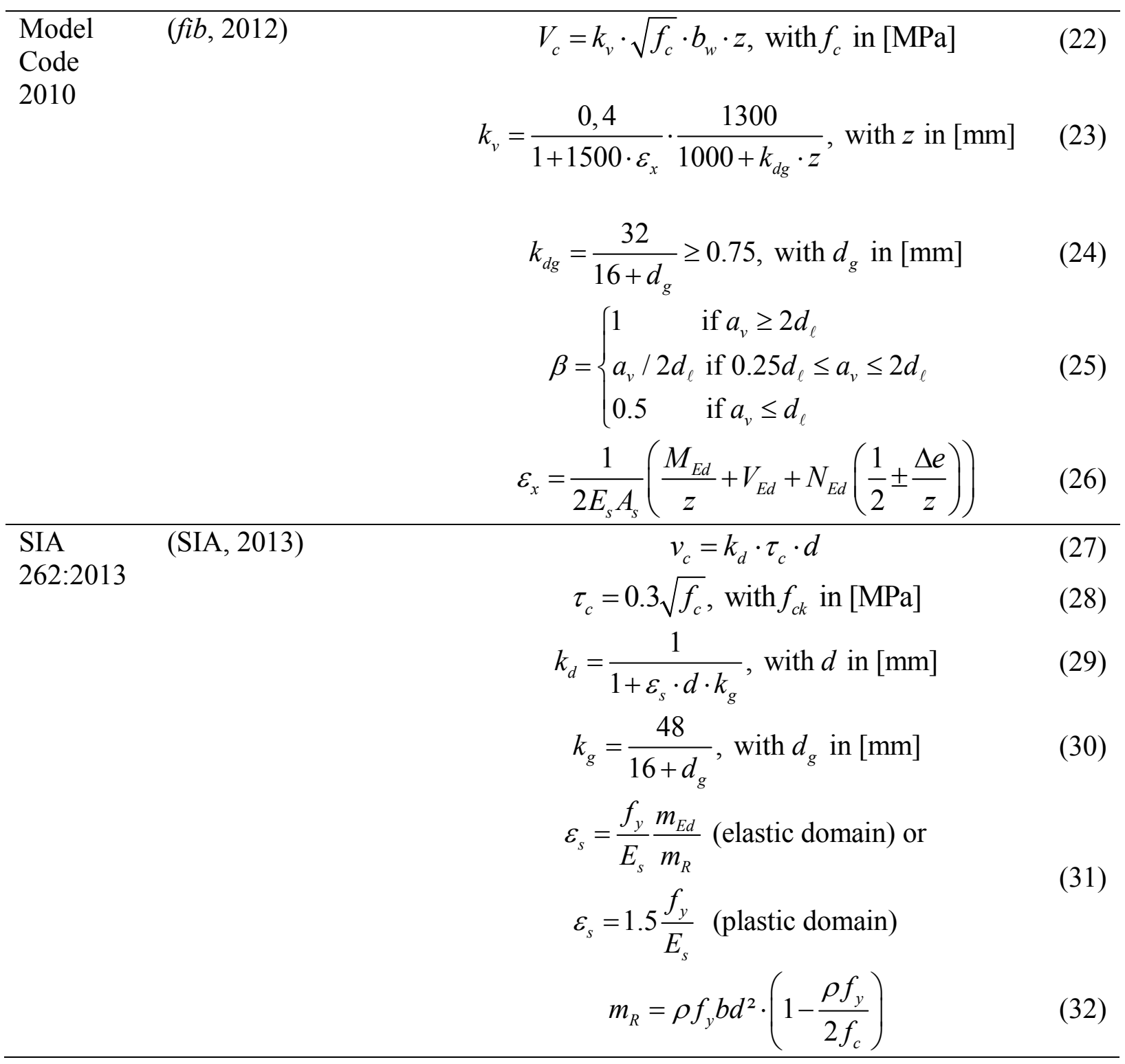


Table 4 - Mechanical models of shear strength - Part II.

\section{Reference Expression}

SFSMM (Marí et

al., 2015)

$$
V_{S f s m m}=\left(v_{c}+v_{w}+v_{l}+v_{s}\right) \cdot f_{c t} \cdot b \cdot d
$$

$$
\begin{gathered}
v_{c}=\frac{V_{c}}{f_{c t} \cdot b \cdot d}=\zeta \cdot(088 \cdot x / d+0.02)(0.94+0.3 \mu) \\
v_{w}=\frac{V_{w}}{f_{c t} \cdot b \cdot d}=167 \cdot \frac{f_{c t}}{E_{c}} \cdot\left(1+\frac{2 \cdot E_{c} \cdot G_{f}}{f_{c t}{ }^{2} \cdot d}\right) \\
v_{l} \simeq 0.23 \frac{\alpha_{e} \rho}{1-\xi} \simeq 0.25 \xi-0.05 \\
v_{s}=\frac{0.85 \cdot d \cdot A_{s w} \cdot f_{y w}}{f_{c t} \cdot b \cdot d}=0.85 \cdot \rho_{w} \cdot \frac{f_{y w}}{f_{c t}} \\
\zeta=1.2-0.2 a \geq 0.65, \text { with } a \text { in }[\mathrm{m}]
\end{gathered}
$$

$$
f_{c t m}=\left\{\begin{array}{l}
0.30 \cdot \sqrt{f_{c k}}, \text { if } f_{c k} \leq 60 M P a \\
2.12 \cdot \ln \left(1+\frac{f_{c m}}{10}\right), \text { if } f_{c k}>60 M P a
\end{array}\right.
$$

$$
E_{c}=22 \cdot\left(\frac{f_{c m}}{10}\right)^{0,3}
$$

$$
G_{f}=0.028 \cdot f_{c m}^{0.18} \cdot d_{g}^{0.32}
$$

$$
\begin{gathered}
s_{u}=s_{c r}+0,85 d \\
\mu=\frac{M}{f_{c t} \cdot b \cdot d^{2}}, \text { for } M=M_{c r} \rightarrow \mu=0.20
\end{gathered}
$$

$$
\xi=\frac{x}{d}=\alpha_{e} \cdot \rho \cdot\left(-1+\sqrt{1+\frac{2}{\alpha_{e} \cdot \rho}}\right)
$$

$$
\alpha_{e}=E_{s} / E_{c}
$$

$\begin{array}{ll}\text { CCCM } & \begin{array}{l}\text { Antoni } \\ \text { Cladera et } \\ \text { al., 2016) }\end{array} \quad V_{C C C M}=0.3 \zeta \frac{x}{d} f_{c}^{2 / 3} b d \geq V_{c u, \min }=0.25\left(\zeta k_{c}+\frac{20}{d_{0}}\right) f_{c}^{2 / 3} b d\end{array}$

$$
\begin{gathered}
\zeta=\frac{2}{\sqrt{1+\frac{d_{0}}{200}}}\left(\frac{d}{a}\right)^{0.2} \nless 0.45, \text { with } d_{0} \text { in }[\mathrm{mm}] \\
\frac{x_{0}}{d}=\alpha_{e} \rho\left(-1+\sqrt{1+\frac{2}{\alpha_{e} \rho}}\right) \simeq 0.75\left(\alpha_{e} \rho_{l}\right)^{1 / 3}
\end{gathered}
$$


Table 5 - Mechanical models of shear strength - Part III.

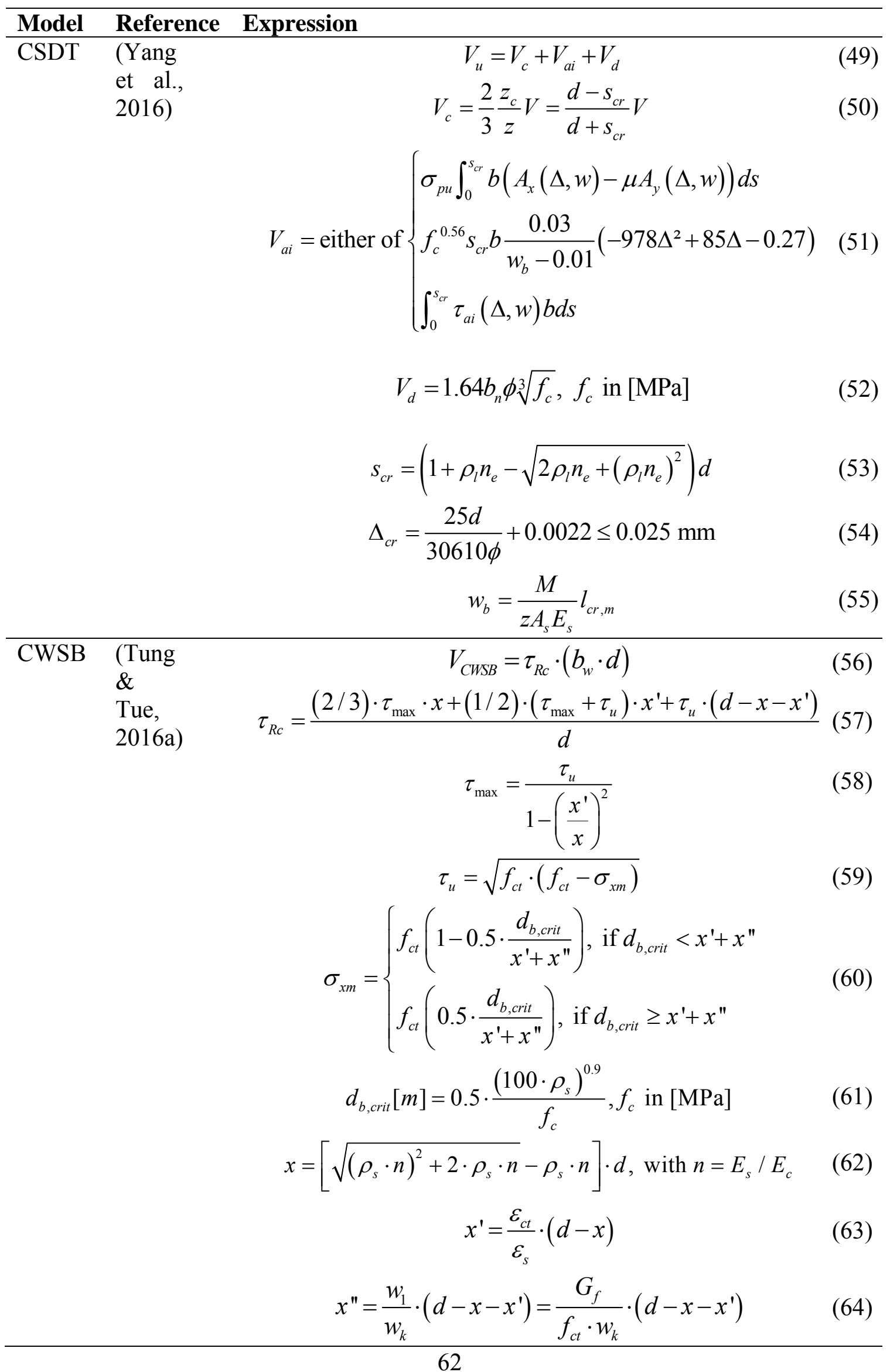




$$
\begin{gathered}
\varepsilon_{c t}=f_{c t} / E_{c} \\
\varepsilon_{s}=\frac{1}{E_{s} \cdot \rho_{s} \cdot b_{w} \cdot d} \cdot\left(\frac{M}{z}+\frac{V}{2}\right) \leq \frac{1}{E_{s} \cdot \rho_{s} \cdot b_{w} \cdot d} \cdot \frac{M_{\max }}{z} \\
w_{k}=s_{r m} \cdot\left(\varepsilon_{s m}-\varepsilon_{c m}\right)=s_{r m} \cdot \frac{1}{E_{s}} \cdot \sigma_{s}-\left[0.5 \cdot \frac{f_{c t}}{\rho_{\rho, \text { eff }}} \cdot\left(1+n \cdot \rho_{\rho, \text { eff }}\right)\right] \\
w_{1}=G_{f} / f_{c t} \\
\rho_{\rho, \text { eff }} \approx 4 \cdot \rho_{s} \\
s_{r m}=0.7 \cdot d
\end{gathered}
$$

Control section:

$$
\begin{gathered}
x_{0}=\frac{M_{c r}}{P}+s_{r m} \cdot\left(1.3-\frac{M_{\max }}{M_{y}}\right) \leq \frac{M_{c r}}{P}+s_{r m} \\
x_{\text {control }}=x_{1}=x_{0}+s_{r m}
\end{gathered}
$$

With $f_{c}$ and $f_{c t}$ in [MPa], $M, M_{c r}$ and $M_{\text {max }}$ in [kNm]

Continuation of Table 5 
Table 6 - Ranges of parameters in database.

\begin{tabular}{ccc}
\hline Parameter & Min & Max \\
\hline$b(\mathrm{~m})$ & 0.21 & 2.40 \\
\hline$h(\mathrm{~m})$ & 0.10 & 1.01 \\
\hline$\ell_{\text {span }}(\mathrm{m})$ & 0.60 & 7.00 \\
\hline$b / d[-]$ & 1.00 & 9.90 \\
\hline$\rho_{\ell}(\%)$ & 0.42 & 2.75 \\
\hline$d_{\ell}(\mathrm{m})$ & 0.085 & 0.916 \\
\hline$\varnothing_{\ell}(\mathrm{mm})$ & 10 & 30 \\
\hline$s / d[-]$ & 0.11 & 1.48 \\
\hline$f_{c}(\mathrm{MPa})$ & 13.40 & 74.62 \\
\hline$d_{a g}(\mathrm{~mm})$ & 10 & 30 \\
\hline$a / d[-]$ & 1.25 & 6.07 \\
\hline$a_{v} / d[-]$ & 0.94 & 5.61 \\
\hline$M / V d[-]$ or $\lambda[-]$ & 1.25 & 11.70 \\
\hline & &
\end{tabular}


Table 7 - Shear behavior of wide RC members according to the parameters studies showed in Figure 10.

\begin{tabular}{|c|c|}
\hline Par. & Observation \\
\hline$\rho_{\ell}$ & $\begin{array}{l}\text { Some models consider the positive effect of longitudinal reinforcement by controlling the shear } \\
\text { crack opening (fib, 2012; Fernández Ruiz et al., 2015; SIA, 2013). On the other hand, others also } \\
\text { take into account the higher dowel action due to higher longitudinal reinforcement ratios (Yang et } \\
\text { al., 2016). Figure 10a shows an increase in the shear strength of wide members for higher } \\
\text { reinforcement ratios, which confirms the importance of this parameter. }\end{array}$ \\
\hline$d$ & $\begin{array}{l}\text { Figure 10b shows the significant effect of the size effect (Bazant \& Kim, 1984; Walraven \& } \\
\text { Lehwalter, 1994), which reduces the normalized shear stress for higher member thickness. } \\
\text { However, the small number of members with thicknesses } d>0.5 \mathrm{~m} \text { hamper the development of } \\
\text { well-accepted formulations. }\end{array}$ \\
\hline$a_{v} / d$ & $\begin{array}{l}\text { Regarding concentrated loads at } a_{\sqrt{ }} / d<2.5 \text {, the formation of compressive struts helps the shear } \\
\text { force transfer directly towards to the support (Lantsoght et al., 2013; Vollum \& Fang, 2015). } \\
\text { Therefore, many design codes enable reductions in the shear design load or increase in the shear } \\
\text { capacity (CEN, 2005; Fédération Internationale du Béton (fib), 2012). Such a procedure is } \\
\text { important in the assessment of existing bridges (Lantsoght et al., 2013). Figure 10c shows } \\
\text { compressive struts play a key role in increasing the shear strength of wide members for } \\
\text { concentrated loads close to the support. }\end{array}$ \\
\hline$M / V d$ & $\begin{array}{l}\text { The } M / V d \text { ratio can be combined with longitudinal reinforcement ratio } \rho_{\mathrm{s}} \text { for accounting the } \\
\text { section strains in shear strength analyses (Zsutty, 1968; ACI-ASCE Committee 326, 1962a, } \\
1962 \mathrm{~b}, 1962 \mathrm{c} \text { ). In models based on MCFT and CSCT, reinforcement strains } \varepsilon_{\mathrm{s}} \text { are directly } \\
\text { considered. Figure 10d shows an increase in } M / V d \text { reduces the shear strength of wide members. } \\
\text { Higher } M / V d \text { values result in larger crack openings of the critical shear crack, which reduces the } \\
\text { contribution of the aggregate interlock to the shear strength. However, the compression chord can } \\
\text { benefit from larger compressive stresses in the uncracked compression zone in cantilever } \\
\text { members under distributed loads (Tung \& Tue, 2016b). Therefore, not always will members } \\
\text { under larger } M / V d \text { ratios show lower shear capacities, as the main shear transfer mechanism may } \\
\text { vary according to the structural system and load arrangement. }\end{array}$ \\
\hline$s / d$ & $\begin{array}{l}\text { The rebar spacing-to-effective depth ratio } s / d \text { is commonly discussed in design codes with upper } \\
\text { limits for guaranteeing the monolithic behavior of RC members. Figure } 10 \mathrm{e} \text { shows the limited } \\
\text { influence of } s / d \text { ratio over the shear strength, which is similar to the results of Gurutzeaga et al. } \\
\text { (2015) and Conforti et al. (2017). The results indicate in such a range of } s / d \text { ratios, the behavior } \\
\text { of wide members can be governed by a plane stress state, mainly if } s / d \text { ratio is smaller than } 1 \text {. } \\
\text { Only some tests reported by Gurutzeaga et al. (2015) revealed cracked surfaces with a more } \\
\text { irregular profile (undulations along the member width) for members with } s / d \text { ratio close to } 1.5 \\
\text { (I/S/316/t.r and I/S/316/0 tests). Gurutzeaga et al. (2015) attribute possible tridimensional shear } \\
\text { carrying mechanisms, formed by inclined struts that extend from the uncracked compression zone } \\
\text { to the reinforcement, to higher } s / d \text { ratios. Such inclined struts result in a three-dimensional state } \\
\text { of stress that justifies a more irregular profile of the shear crack along the width direction. } \\
\text { Furthermore, due to the larger surface of contact created by the undulations in the shear crack, the } \\
\text { aggregate interlock may be improved. }\end{array}$ \\
\hline
\end{tabular}




\begin{tabular}{|l|l|}
$b / d$ & $\begin{array}{l}\text { Models of shear strength used for RC wide members without shear reinforcement are usually } \\
\text { based on beam tests. Figure } 10 \mathrm{f} \text { shows the } b / d \text { ratio of the tests in the investigated range presented } \\
\text { a lower influence than other parameters, which contradicts some results from Conforti et al. } \\
\text { (2017). These authors found higher shear capacities for members with a } b / d \text { ratio between } 2 \text { and }\end{array}$ \\
3. In tests with $b / d>2$, Conforti et al. (2017) and Adam et al. (2018) observed the cracked faces \\
can be more irregular, with some undulations and bumps along the member width. Such larger \\
cracked surfaces con offer some benefits in aggregate interlock that explain the higher shear \\
capacities measured by Conforti et al. (2017) for simply supported members. On the other hand, \\
when a critical shear crack arises closer to the inner support of continuous members, the \\
aggregate interlock assumes minor importance and no significant improvement in their shear \\
strength is expected.
\end{tabular}


Table 8 - Behavior of $\mathrm{RC}$ members according to the degree of rotational restraint at the support and the load arrangement: (CL) members subjected to concentrated loads and (DL) members subjected to uniformly distributed loads.

\begin{tabular}{|c|c|c|c|}
\hline $\begin{array}{l}\text { Load } \\
\text { arrangement }\end{array}$ & $\begin{array}{c}\lambda \\
{[-]}\end{array}$ & $d_{r}(\%)$ & Behavior \\
\hline CL & $<2.5$ & $0-50 \%$ & $\begin{array}{l}\text { The normalized shear strength of wide members increases between } \\
25 \% \text { and } 69 \% \text { when } d_{r} \text { increases from } 0 \% \text { (simply-supported } \\
\text { members) to almost } 50 \% \text { for tests under concentrated loads (CL), } \\
\text { thus indicating greater benefits from direct compressive struts. }\end{array}$ \\
\hline DL & $<4$ & $0-75 \%$ & $\begin{array}{l}\text { In members under distributed loads (DL), the shear capacities } \\
\text { increase from } 39 \% \text { to } 62 \% \text { when } d_{r} \text { increases from } 0 \text { to } 75 \% \text {. For } d_{r} \\
<75 \% \text {, the continuous specimens show higher bending moments in } \\
\text { the span }\left(M_{\text {sup }}<M_{\text {span }}\right) \text { and the critical shear crack develops far } \\
\text { from the internal support, thus resulting in better activation of } \\
\text { aggregate interlock (Cavagnis et al., 2018) and higher shear } \\
\text { capacities. In such cases, the continuous member's behavior is } \\
\text { similar to that of simply supported members with a reduced shear } \\
\text { span (Tung \& Tue, 2016b). }\end{array}$ \\
\hline CL & $2-3$ & $50-100 \%$ & $\begin{array}{l}\text { An increase in } d_{r} \text { from } 50 \% \text { to } 100 \% \text { reduces approximately } 23 \% \\
\text { of the normalized shear strength of continuous members under } \\
\text { concentrated loads (CL). Since at the initial range, an increase in } \\
\text { the } d_{r} \text { reduces the shear slenderness up to a limit. Beyond this limit, } \\
\text { an increase in } d_{r} \text { increases the shear slenderness. However, the } \\
\text { shear strength of fully clamped members }\left(d_{r}=100 \%\right) \text { is, in general, } \\
\text { higher than that of simply-supported members }\left(d_{r}=0\right) \text {, which may } \\
\text { indicate benefits in the shear strength provided by different } \\
\text { structural systems and load arrangements. }\end{array}$ \\
\hline DL & $2-4$ & $75-100 \%$ & $\begin{array}{l}\text { For members under DL, the shear capacities are reduced by } \\
\text { approximately } 46 \% \text { when } d_{r} \text { increases from } 75 \% \text { to } 100 \% \text {, since at } \\
d_{r} \text { closer to } 100 \% \text { the critical shear crack develops closer to the } \\
\text { internal support, thus reducing the contribution from the aggregate } \\
\text { interlock (Cavagnis et al., 2018). For } d_{r} \text { closer to } 100 \% \text {, the critical } \\
\text { shear cracks closer to the internal support limits the formation of } \\
\text { direct compressive struts (Yang et al. (2017). For such cases, a } \\
\text { behavior similar to that of cantilever members loaded at the point } \\
\text { of inflection is assumed (Tung \& Tue, 2016b). }\end{array}$ \\
\hline CL & $>2.7$ & $0-100 \%$ & $\begin{array}{l}\text { For members under CL and more susceptible to flexural shear } \\
\text { failures, } \lambda>2.7 \text {, no significant differences in the shear strength are } \\
\text { observed when } d_{r} \text { increases from } 0 \text { to } 100 \% \text {, which agrees with the } \\
\text { results presented in Figure } 11 \text { and others studies (Reißen, 2016). }\end{array}$ \\
\hline
\end{tabular}


Table 9 - Statistical evaluation of the $V_{\text {exp }} / V_{\text {cal }}$ ratio with semi-empirical models according to the structural system.

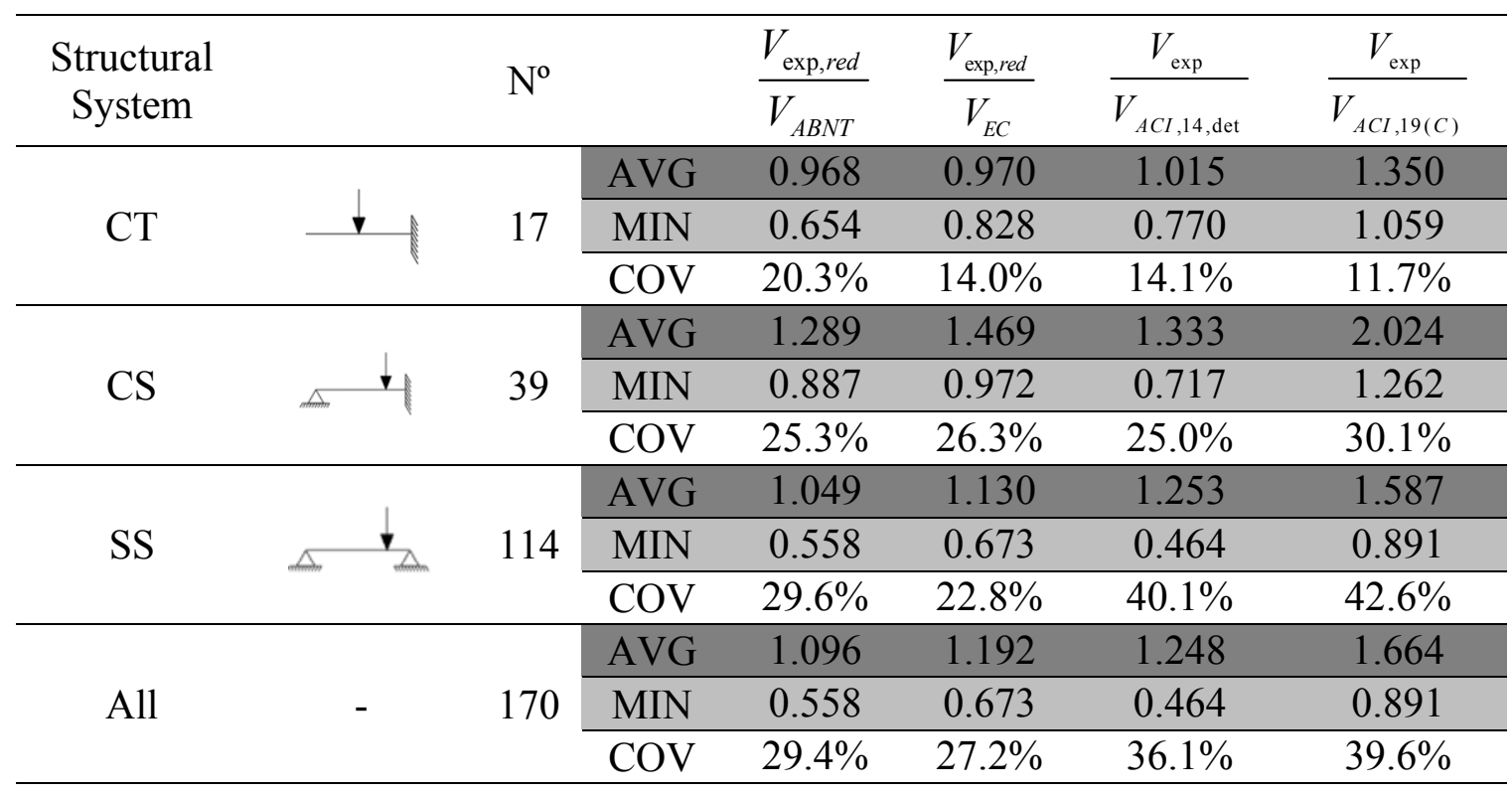


Table 10 - Statistical evaluation of the $V_{\text {exp }} / V_{c a l}$ ratio with mechanical models according to the structural system.

\begin{tabular}{|c|c|c|c|c|c|c|c|c|c|}
\hline $\begin{array}{l}\text { Structural } \\
\text { System }\end{array}$ & & $\mathrm{N}^{\circ}$ & & $\frac{V_{\text {exp,red }}}{V_{M C}}$ & $\frac{V_{\text {exp }, \text { red }}}{V_{S I A}}$ & $\frac{V_{\text {exp }, \text { red }}}{V_{S F S M M}}$ & $\frac{V_{\text {exp }, \text { red }}}{V_{C C C M}}$ & $\frac{V_{\text {exp,red }}}{V_{C S D T}}$ & $\frac{V_{\text {exp,red }}}{V_{C W S B}}$ \\
\hline \multirow{3}{*}{$\mathrm{CT}$} & \multirow{3}{*}{$\checkmark 1$} & \multirow{3}{*}{17} & AVG & 1.169 & 1.069 & 0.927 & 1.142 & 1.227 & 1.001 \\
\hline & & & MIN & 0.959 & 0.821 & 0.726 & 0.846 & 0.894 & 0.824 \\
\hline & & & $\mathrm{COV}$ & $15.0 \%$ & $13.8 \%$ & $14.3 \%$ & $13.6 \%$ & $13.8 \%$ & $11.2 \%$ \\
\hline \multirow{3}{*}{$\mathrm{CS}$} & \multirow{3}{*}{$\triangle \quad 4$} & \multirow{3}{*}{39} & $\overline{A V G}$ & 1.404 & 1.225 & 1.326 & 1.455 & 1.235 & 1.063 \\
\hline & & & MIN & 0.885 & 0.876 & 0.906 & 1.000 & 0.884 & 0.765 \\
\hline & & & $\mathrm{COV}$ & $20.3 \%$ & $17.6 \%$ & $24.9 \%$ & $22.1 \%$ & $18.9 \%$ & $20.2 \%$ \\
\hline \multirow{3}{*}{$\mathrm{SS}$} & \multirow{3}{*}{$\triangle \quad \nabla_{\Delta}$} & \multirow{3}{*}{114} & AVG & 1.213 & 1.103 & 1.060 & 1.202 & 1.102 & 1.170 \\
\hline & & & MIN & 0.791 & 0.737 & 0.697 & 0.776 & 0.827 & 0.761 \\
\hline & & & $\mathrm{COV}$ & $17.5 \%$ & $18.4 \%$ & $20.3 \%$ & $19.5 \%$ & $13.6 \%$ & $26.3 \%$ \\
\hline \multirow{3}{*}{ All } & & \multirow{3}{*}{170} & $\overline{A V G}$ & 1.252 & 1.127 & 1.108 & 1.254 & 1.145 & 1.129 \\
\hline & & & MIN & 0.791 & 0.737 & 0.697 & 0.776 & 0.827 & 0.761 \\
\hline & & & $\mathrm{COV}$ & $19.3 \%$ & $18.4 \%$ & $24.4 \%$ & $21.8 \%$ & $16.0 \%$ & $24.8 \%$ \\
\hline
\end{tabular}


Table 11 - Statistical evaluation of the $V_{\text {exp }} / V_{c a l}$ ratio with mechanical models according to the $b / d$ ratio.

\begin{tabular}{|c|c|c|c|c|c|c|c|c|}
\hline$b / d$ & $\mathrm{~N}^{\circ}$ & & $\frac{V_{\text {exp,red }}}{V_{M C}}$ & $\frac{V_{\text {exp }, \text { red }}}{V_{S I A}}$ & $\frac{V_{\text {exp }, \text { red }}}{V_{S f s m m}}$ & $\frac{V_{\text {exp }, \text { red }}}{V_{C C C M}}$ & $\frac{V_{\text {exp }, \text { red }}}{V_{C S D T}}$ & $\frac{V_{\text {exp }, \text { red }}}{V_{C W S B}}$ \\
\hline \multirow{3}{*}{$1 \leq b / d \leq 2.5$} & \multirow{3}{*}{108} & $\overline{\mathrm{AVG}}$ & 1.259 & 1.139 & 1.150 & 1.295 & 1.184 & 1.090 \\
\hline & & MIN & 0.791 & 0.794 & 0.802 & 0.776 & 0.827 & 0.765 \\
\hline & & $\mathrm{COV}$ & $21.2 \%$ & $18.2 \%$ & $25.8 \%$ & $22.3 \%$ & $15.5 \%$ & $21.5 \%$ \\
\hline \multirow{3}{*}{$2.5<b / d \leq 5$} & \multirow{3}{*}{42} & $\overline{A V G}$ & 1.239 & 1.120 & 1.030 & 1.178 & 1.058 & 1.239 \\
\hline & & MIN & 0.911 & 0.737 & 0.697 & 0.810 & 0.835 & 0.824 \\
\hline & & $\mathrm{COV}$ & $14.9 \%$ & $20.0 \%$ & $19.5 \%$ & $20.6 \%$ & $15.2 \%$ & $27.6 \%$ \\
\hline \multirow{3}{*}{$b / d>5$} & \multirow{3}{*}{20} & AVG & 1.243 & 1.079 & 1.043 & 1.193 & 1.116 & 1.107 \\
\hline & & MIN & 0.993 & 0.891 & 0.760 & 0.874 & 0.924 & 0.761 \\
\hline & & $\mathrm{COV}$ & $16.3 \%$ & $15.5 \%$ & $18.2 \%$ & $16.4 \%$ & $14.3 \%$ & $28.7 \%$ \\
\hline \multirow{3}{*}{ All } & \multirow{3}{*}{170} & $\mathrm{AVG}$ & 1.252 & 1.127 & 1.108 & 1.254 & 1.145 & 1.129 \\
\hline & & MIN & 0.791 & 0.737 & 0.697 & 0.776 & 0.827 & 0.761 \\
\hline & & $\mathrm{COV}$ & $19.3 \%$ & $18.4 \%$ & $24.4 \%$ & $21.8 \%$ & $16.0 \%$ & $24.8 \%$ \\
\hline
\end{tabular}


Table 12 - Statistical evaluation of the $V_{\text {exp }} / V_{\text {cal }}$ ratio with mechanical models according to the shear slenderness $\lambda$.

\begin{tabular}{|c|c|c|c|c|c|c|c|c|}
\hline Range & $\mathrm{N}^{\circ}$ & & $\frac{V_{\text {exp }, \text { red }}}{V_{M C}}$ & $\frac{V_{\text {exp }, \text { red }}}{V_{S I A}}$ & $\frac{V_{\text {exp }, \text { red }}}{V_{S f s m m}}$ & $\frac{V_{\text {exp }, \text { red }}}{V_{C C C M}}$ & $\frac{V_{\text {exp }, \text { red }}}{V_{C S D T}}$ & $\frac{V_{\text {exp }, \text { red }}}{V_{C W S B}}$ \\
\hline \multirow{3}{*}{$\lambda<3$} & \multirow{3}{*}{94} & AVG & 1.323 & 1.170 & 1.205 & 1.330 & 1.162 & 1.201 \\
\hline & & MIN & 0.791 & 0.794 & 0.802 & 0.776 & 0.827 & 0.761 \\
\hline & & $\mathrm{COV}$ & $20.0 \%$ & $19.2 \%$ & $25.4 \%$ & $23.3 \%$ & $17.5 \%$ & $27.8 \%$ \\
\hline \multirow{3}{*}{$\lambda \geq 3$} & \multirow{3}{*}{76} & $\mathrm{AVG}$ & 1.165 & 1.074 & 0.988 & 1.161 & 1.124 & 1.039 \\
\hline & & MIN & 0.882 & 0.737 & 0.697 & 0.810 & 0.835 & 0.771 \\
\hline & & $\mathrm{COV}$ & $12.8 \%$ & $15.0 \%$ & $14.9 \%$ & $15.8 \%$ & $13.8 \%$ & $15.1 \%$ \\
\hline \multirow{3}{*}{ All } & \multirow{3}{*}{170} & $\mathrm{AVG}$ & 1.252 & 1.127 & 1.108 & 1.254 & 1.145 & 1.129 \\
\hline & & MIN & 0.791 & 0.737 & 0.697 & 0.776 & 0.827 & 0.761 \\
\hline & & $\mathrm{COV}$ & $19.3 \%$ & $18.4 \%$ & $24.4 \%$ & $21.8 \%$ & $16.0 \%$ & $24.8 \%$ \\
\hline
\end{tabular}

